NBER WORKING PAPER SERIES

\title{
THE COLLATERAL CHANNEL OF MONETARY POLICY: EVIDENCE FROM CHINA
}

\author{
Hanming Fang \\ Yongqin Wang \\ $\mathrm{Xian} \mathrm{Wu}$ \\ Working Paper 26792 \\ http://www.nber.org/papers/w26792 \\ NATIONAL BUREAU OF ECONOMIC RESEARCH \\ 1050 Massachusetts Avenue \\ Cambridge, MA 02138 \\ February 2020
}

We thank Tri Vi Dang, Zhiguo He, Guillermo Ordonez, Gregory Phelan, Jian Wang, Wei Xiong, Tianran Zhao, seminar participants at CUHK (Shenzhen), Fudan University, ShanghaiTech University, and University of Pennsylvania, and professionals in the Chinese bond markets for helpful comments. We are responsible for all remaining errors. The views expressed herein are those of the authors and do not necessarily reflect the views of the National Bureau of Economic Research.

NBER working papers are circulated for discussion and comment purposes. They have not been peer-reviewed or been subject to the review by the NBER Board of Directors that accompanies official NBER publications.

(C) 2020 by Hanming Fang, Yongqin Wang, and Xian Wu. All rights reserved. Short sections of text, not to exceed two paragraphs, may be quoted without explicit permission provided that full credit, including $\odot$ notice, is given to the source. 
The Collateral Channel of Monetary Policy: Evidence from China

Hanming Fang, Yongqin Wang, and Xian Wu

NBER Working Paper No. 26792

February 2020

JEL No. E44,E52,E58,G12

\begin{abstract} reduced by 54 basis points.

Hanming Fang

Department of Economics

Ronald O. Perelman Center

for Political Science and Economics

133 South 36th Street

Suite 150

Philadelphia, PA 19104

and NBER

hanming.fang@econ.upenn.edu

Yongqin Wang

No. 600, Guoquan Road

School of Economics

Fudan University

Shanghai, China

yongqinwang@fudan.edu.cn

\author{
Xian Wu \\ Department of Economics \\ University of Wisconsin \\ Social Science Building \\ 1180 Observatory Drive \\ Madison, WI 53706 \\ xwu394@wisc.edu
}

Collateral-based monetary policy tools have been used extensively by major central banks. Lack of proper policy counterfactuals, however, makes it difficult to empirically identify their causal effects on the financial market and the real economy. We exploit a quasi-natural experiment in China, where dual-listed bonds are traded in two mostly segmented markets: the interbank market regulated by the Central Bank, and the exchange market regulated by the securities regulator. During a policy shift in our study period, China's Central Bank included a class of previously ineligible bonds in the interbank market to become eligible collateral for financial institutions to borrow money from its Medium-Term Lending Facility (MLF). This policy shift allows us to implement a triple-difference strategy to estimate the causal impact of the collateral-based unconventional monetary policy. We find that in the secondary market the policy reduced the spreads of the newly collateralizable bonds in the treatment market (the interbank market) by 42-62 basis points. We also find that there is a pass-through effect from the secondary market to the primary market: the spreads of the treated bonds newly issued in the interbank market were 
"The main business of Wall Street is to help make and keep promises. Overtime, as more people have been included in the process, punishment and reputation have been replaced by collateral."

John Geanakoplos (1997)

\section{Introduction}

One big lesson from the Global Financial Crisis (GFC) is the important role of collateral and leverage in the modern financial and monetary systems. Collateral is at the heart of the shadow banking system and the repo run in the GFC (Geanakoplos, 2010; Gorton and Metrick, 2012). In the modern collateral-based financial system, a financial contract can be viewed as a pair of a "promise" and "collateral" (broadly defined) to back up the promise; moreover, contracts themselves can be used as collaterals for new promises. In the financial market equilibrium, both interest rates (spread) and leverage are endogenously determined (Geanakoplos, 2010). When investors use a combination of equity and debt to finance the purchase of the assets, which are in turn used as collateral for the debt, the leverage ratio is simply the ratio of debt over equity. For example, if the lenders allow the investor to borrow up to $80 \%$ of the asset value, i.e. if the haircut is $20 \%$, the leverage is simply $1 /$ haircut $=5$. Haircuts reflect the lenders' fear that the value of the collateral will fall in the future.

The leverage cycle theory (Geanakoplos, 2010; Fostel and Geanakoplos, 2012; Gorton and Metrick, 2012) is hugely influential in at least two fronts. First, it emphasizes that leverage is a crucial determinant of asset prices, even more important than interest rate. Leverage-induced boom-bust cycles arguably have led to financial fragility and recurring financial crises. For example, margin finance is closely related to the Great Depression of 1929-1933, and the Great Recession following the 2008 sub-prime crisis (Galbraith, 2009; Fostel and Geanakoplos, 2012). The liquidity dry-up in the repo run during the GFC was mostly through the deleveraging mechanism (Gorton and Metrick, 2012 ).

Second, the leverage cycle theory also has important implications for monetary policy. Before the GFC, central banks focus more closely on interest-rate based or interest-rate targeted policy tools such as rediscounting policy and open market operations. After the GFC, collateral-based monetary policy tools have been extensively deployed by major central banks. For instance, the Federal Reserve launched the Term Asset-Backed Securities Loan Facility (TALF) in late November 2008, through which the Fed lent up to $\$ 1$ trillion to financial markets against collaterals of asset-backed securities (ABS) and loans guaranteed by Small Business Administration. This was followed by two additional rounds, respectively announced in November 2010 and September 2012, of what have been referred to as "Quantitative Easing" (QE) whereby the Federal Reserve buys predetermined amounts of government bonds or other financial assets in order to inject liquidity directly into 
the economy!1 After the GFC, the European Central Bank launched the Long-term Refinancing Operations (LTROs) aimed to reduce sovereign bond spreads and inject liquidity into the market, where it provides low interest rate funding to Eurozone banks collateralized by sovereign debt.

Unconventional collateral-based monetary policy tools have been invoked for at least two reasons. First, from a theoretical point of view, the collateral-based monetary policy can be used by the central bank to ease the heightened funding constraint and to reverse the deleveraging cycle in the financial system (Geanakoplos, 2010; Ashcraft et al., 2011). Second, from a practical point of view, once the zero-lower-bound (ZLB) constraint of short-term rate begins to bind, which renders ineffective the interest rate-based tools, collateral-based tools seem to be a natural alternative.

Despite the theoretical appeal and broad deployment of the unconventional collateral-based monetary policy during and after the GFC, it is empirically difficult to identify its causal impact on the financial markets and the real economy. The main challenge is the lack of proper policy counterfactuals (see (Nakamura and Steinsson, 2018)). There are several reasons for the empirical challenge. First, in the leverage cycle theory, both the interest rate (spread) and leverage (or haircut) are endogenously determined in equilibrium. Thus, the empirical relationship between haircuts and spread in the typical bond market data is not causal. Second, the timing of central banks' implementation of collateral-based monetary policy is not random. Third, the assets that are made eligible or ineligible as collateral for financial and non-financial institutions to borrow from the central banks' lending facilities are not random. For example, in QE1, Federal Reserve decided to purchase "housing-related government-sponsored enterprises (GSEs) - Fannie Mae, Freddie Mac, and the Federal Home Loan Banks - and mortgage-backed securities (MBS) backed by Fannie Mae, Freddie Mac, and Ginnie Mae" and listed the following as the reason for its action: "Spreads of rates on GSE debt and on GSE-guaranteed mortgages have widened appreciably of late."2 As a result, the counterfactual outcomes for the spreads of the collateral assets in question in the absence of the monetary policy intervention are hard to assess, making it difficult to estimate the causal effect of the monetary policy.

In this paper, we present, to the best of our knowledge, the first empirical evidence for the causal impact of the collateral-based monetary policy on the financial markets and the real economy. We are able to identify the causal impact of collateral-based monetary policy, using a triple-difference empirical design, by exploiting a unique feature of China's bond market and a policy intervention by China's Central Bank. The unique feature of China's bond market is that most corporate bonds are dual-listed in two trading platforms: the interbank market and the exchange market. These two platforms are subject to different regulations and differentially affected by monetary

\footnotetext{
${ }^{1}$ Buiter (2008) makes the distinction between "Quantitative Easing" and "Qualitative Easing." He defines the former as an increase in the size of central bank's balance sheet, holding constant the composition of its assets; and defines the latter as a shift in the composition of the assets of the central bank towards less liquid and riskier assets, holding constant the size of the balance sheet. US Federal Reserve's policy is both quantitative and qualitative easing in his sense.

${ }^{2}$ See the Fed's announcement of QE1 on November 25, 2008: https://www.federalreserve.gov/newsevents/pressreleases/monetary20081125b.htm.
} 
policy interventions, and most importantly, are largely segmented due to difficulties in arbitrage. As a result, even though the dual-listed bonds have exactly the same fundamentals, they can have different prices or spreads in the two markets, due to different liquidity in the two markets for example (see Section 3 for more institutional details) $]^{3}$ On June 1, 2018, People's Bank of China (PBOC), which is China's central bank, for the first time made corporate bonds and some financial bonds rated $\mathrm{AA}$ and $\mathrm{AA}+$ eligible as collateral for financial institutions to borrow from its Medium-Term Lending Facilities (MLF) in the interbank market. Importantly, the policy does not apply in the exchange market. Note that all corporate bonds with AAA ratings have always been eligible collateral for MLF. This enables us to implement a triple-difference (DDD) approach to examine the effect of the collateral-based monetary policy. By comparing the changes, before and after the policy shock, in the difference of spreads of the newly collateral-eligible bonds (the treatment bonds) and other bonds (the control bonds) between the two markets, we are able to identify the causal effects of the collateral-based monetary policy on the financial market and the real economy. The changes in the difference in the spreads between the "control" and "treatment" bonds in the exchange market (which serves as the role of "policy counterfactual" or the "placebo") reflect the possibly differential impact of time-varying factors on the two groups of bonds.4 Under the plausible assumption that the same differential impact of the time-varying factors on the control and treatment bonds applies in the interbank market and the exchange market, then we can use the "placebo effect" estimated from the exchange market to tease out the effect of the time-varying factors in the interbank market. Note that, for our empirical identification strategy, it is crucial that the interbank market and the exchange market are segmented; otherwise, the policy intervention in the interbank market would impact the pricing of the dual-listed bonds in the exchange market, thus contaminating the "placebo."

We find that the collateral-based monetary policy effectively decreases the spreads of bonds in interbank market. The policy leads to an average reduction of the spreads of the newly collateralizable bonds by 42-62 basis points (bps) - which is about 13 to 20 percent of the mean spreads in the interbank market comparing to the dual-listed bonds in the exchange market. Interestingly, we also find that the funding cost reduction in the interbank market is not restricted to the newly collateral-eligible bonds, in fact, the overall funding cost of the interbank market falls in general due to generally more available collateral in the market. We further decompose the bond spread into liquidity risk premium and default risk premium, and find that the reduction in the spreads of the treated bonds in the interbank market is mostly attributed to a reduction in the perceived default risk instead of the liquidity risk. This is consistent with the leverage theory a la Geanakoplos (2010), which argues that the a lower haircut of the collateral increases the leverage of the optimists, and in turn pushes up the asset prices. It is also consistent with the view that the treated bonds are less likely to default because the funding costs of rolling over these bonds are now lower.

\footnotetext{
${ }^{3}$ We provide empirical evidence for the market segmentation in Section 4.3 .

${ }^{4}$ It is important to allow for the time-varying factors to potentially impact the treatment and control bonds differently because, as we mentioned earlier, the treated bonds are not randomly chosen.
} 
We also analyze the pass-through effect of the secondary market policy shock to the primary market (issuance market). We find that making the treated bonds collateral-eligible for MLF in the interbank (secondary) market also reduces their spreads at issuance in the interbank market by 53.8 basis points, ceteris paribus. That is, the pass-through rate is between about $85 \%$ to as high as more than $100 \%$. Since the spread reduction of the newly issued collateral-eligible bonds reflects a reduction in the funding cost of new real investments, our estimated high pass-through rate to the primary bond issuance market thus indicates a real effect of the collateral-based monetary policy.

Our paper makes three contributions to the literature. First, to our knowledge, the paper is the first to use a clean quasi-natural experiment to identify the causal effects of collateral-based monetary policy on asset prices and the real economy. This is important because unconventional monetary policy in general and collateral-based monetary policy in particular have been widely adopted after the GFC. Second, our paper also adds new causal evidence to the existing but scant literature on leverage and asset pricing (see Chen et al. (2018); Hansman et al. (2018); Wang and $\mathrm{Xu}$ (2019), which we discuss in detail below in Section 2). We also contribute to an emerging literature on identification of macroeconomic policies using a clean identification strategy and micro data ((Nakamura and Steinsson, 2018)). Third, this paper finds that the monetary policy not only reduces the spreads of the bonds, but also induces more bonds to be issued in the interbank market. This finding is complementary to several recent papers discussing the borrowing incentive and riskshifting behavior under unconventional monetary policy (Nyborg, 2017b; van Bekkum et al., 2017).

The remainder of the paper is structured as follows. In Section 2, we review the most related literature; in Section 3 we introduce the institutional background of the Chinese bond markets and of the policy change; in Section 4 we analyze the secondary market; in Section 5 we discuss the primary market; and finally, in Section 6 we conclude.

\section{Related Literature}

The paper is related to two strands of literature. The first strand focuses on the roles, both theoretically and empirically, of collateral and leverage on asset pricing and financial cycles. In a series of papers, Geanakoplos and his co-authors (Geanakoplos, 1997, 2010; Geanakoplos and Zame, 2014) lay the theoretical foundations of collateral and leverage in a general equilibrium framework, and draw important implications for asset pricing, financial cycles and financial fragility. Garleanu and Pedersen (2011) apply the ideas to asset pricing. The key idea of the literature is that collateral can mitigate the frictions caused by incomplete contracts and incomplete information, and that every financial contract is a pair of a promise and associated collateral. The equilibrium terms of the contracts consist of both the interest rate (equivalently, spread) and the leverage (equivalently, margin or haircut). Higher asset-based leverage allows the optimists' beliefs to be better reflected in the asset demand and thus push up the asset prices. Higher asset prices also mean that the required return of the asset for the investors is lower. In the primary market, this implies a lower financing cost of the borrowers. 
The empirical literature to test the asset pricing implications of collateral and leverage is emerging but small, mainly because of the difficulty in finding plausibly exogenous sources of variation for leverages (haircuts, or margins). Hansman et al. (2018) attempts to quantify both the direct and indirect effects of leverage on asset prices, by exploiting the unique staggered nature of China's margin lending liberalization from 2010-2015. The direct effect results from the increase in demand for assets by ex-ante constrained investors as a result of higher permissible leverage; and the indirect effect results from the increases in anticipatory speculation by ex-ante unconstrained investors. Two papers that are closely related to our paper are Chen et al. (2018) and Wang and Xu (2019). Chen et al. (2018) exploits a sudden policy change on December 8, 2014 that in the exchange market in China, enterprise bonds with ratings AA+ and AA were no longer accepted as repo collateral. By comparing how bond prices changed across markets and rating classes around this event, Chen et al. (2018) estimates the causal effect of asset pledgeability on prices in the secondary market; and they find that an increase in haircut from 0 to $100 \%$ (which corresponds to the policy shock of unpledgeability of AA+ and AA-rated enterprise bonds) would result in an increase in bond yields in the range of 40 to $83 \mathrm{bps}$. Wang and $\mathrm{Xu}(2019)$, on the other hand, focuses on the impact of repo collateral eligibility on the primary bond issuance market pricing. They use a policy shift by China Central Depository \& Clearing Co. Ltd. on April 7, 2017 that for bonds whose prospectuses were issued after April 7, 2017, only those with bond ratings at AAA or above can be accepted as collateral; prior to the policy shift bonds rated AA or higher were collateral eligible. The policy shift, however, only applies to new bond issuances in the exchange market and not in the interbank market; moreover, it exempts from the new requirement bonds whose prospectuses were published before April 7, 2017. Wang and Xu (2019) finds that AA rated bonds issued after the policy shift in the exchange market had 60-70 bps higher spread in the primary market relative to those whose pledgeability was not affected by the policy shift. Relative to Chen et al. (2018) and Wang and $\mathrm{Xu}(2019)$, we consider the impact of collateral-based monetary policy intervention by the Central Bank in the Medium-Term Liquidity Facility (MLF), and study both the impacts of the monetary policy on bond spreads both in the secondary market and in the primary market (thus the real economy) $5^{5}$ In addition, we consider the impact of an expansion of the collateral eligible bonds for MLF, while Chen et al. (2018) and Wang and $\mathrm{Xu}(2019)$ both consider the tightening of the eligible collaterals.

The second strand of related literature focuses on collateral-based monetary policy. A large literature studies the effects of Quantitative Easing (Gertler and Karadi, 2011; Curdia and Woodford, 2011; Joyce et al., 2012; Maggio et al., 2016; Lenel, 2017; Rodnyansky and Darmouni, 2017; De Fiore et al., 2018; Acharya et al., 2019), where the collateral channel is highlighted as a key to QE. In a theoretical paper, Araújo et al. (2015) introduce the collateral dimension into a monetary policy framework and study an interesting trade-off especially related to quantitative easing by the central banks: the purchase of Treasury Bills can release liquidity to the market, but beyond some

\footnotetext{
${ }^{5}$ In particular, MLF was established by PBOC in September of 2014, which was after the policy shock studied in Chen et al. (2018).
} 
point this may reduce available collateral in the market and reduce liquidity ${ }^{6}$ Lenel (2017) studies how central bank asset purchase (i.e., QE) changes the quantities and the maturity structure of safe assets, which in turn changes interest rates and asset prices, in a model with collateralized lending and an endogenously segmented markets for safe assets. Geanakoplos and Wang (2018) study a model where the Central Bank's balance sheet is owned by individual investors, thus when QE increases the leverage ratio of the Central bank, it also increases the leverage of individual investors. They show that unconventional collateral-based monetary policy that exchanges reserves for lower quality collateral can be beneficial when high-quality collateral is scarce. In a related model of Piazzesi and Schneider (2017), banks borrow or lend in the interbank market, which can either require collateral or use central bank reserves. They show that the provision and allocation of collateral play a fundamental role for liquidity in the payment system.

A small literature in this strand compares the effects of different types of monetary policy. Ashcraft et al. (2011) explicitly study the collateral-based monetary policy targeting the haircut of assets, and compare it with the traditional interest-rate-based monetary policy. Their model implies that when financial institutions are more credit constrained, collateral-based monetary policy tools are more effective than interest-rate-based monetary policy tools. When financial institutions are subject to funding constraints, reducing interest rate may decrease the spread of safe assets with low margins, while increasing the spread of risky assets with high margin, making institutions that hold the risky asset even more credit constrained. In contrast, collateral-based policies that allow higher leverages for risky assets can increase their prices, reduce their required returns for investors, and relax the liquidity constraint facing the financial institutions. Moreover, collateralbased policies can reduce the overall funding costs, since more collateral availability can ease the funding constraints on all assets. De Fiore et al. (2018) compared QE with a policy of unlimited liquidity provision against collateral in an environment with secured and unsecured money markets. Their model shows that, when safe assets are scarce, direct asset purchase is better than lending to banks against collaterals.

Empirical literature on the evaluations of collateral-based unconventional monetary policy is relatively small. Using survey data, Ashcraft et al. (2011) find that TALF eligibility effectively increased the investors' valuation for Commercial Mortgage-Backed Securities (CMBS) bonds. By exploiting weekly data on yield spreads, Ashcraft et al. (2011) also find that spreads of super senior fixed-rate conduit CMBS bonds significantly increased after being unexpectedly rejected from TALF plan. Benetton et al. (2018) study the effects of Targeted Longer-Term Refinancing Operations (TLTROs) by the European Central Bank (ECB) on the financing costs of Italian firms, and find that the interest rates decreased by $20 \mathrm{bps}$ for the loans of banks that accepted TLTROs. Some studies point to some potential distortionary effects of collateral-based monetary policy. For example, Nyborg (2017a) argues that more lax collateral eligibility by ECB creates perverse incentives for the financial institutions to produce low quality assets. In the context of Netherlands, van Bekkum et al. (2017) find when ECB lowered RMBS eligibility to BBB-, banks

\footnotetext{
6 Araújo et al. (2019) further extend the model to a sticky price economy environment.
} 
issued more low-rated RMBS with higher default rates. Studies also show heterogeneous effects of the policies. For instance, Krishnamurthy et al. (2017) find that LTROs reduced the spreads of Spanish sovereign debts, while they had little effect on those of other EU countries. Benetton et al. (2018) find that the effects of TLTROs depend on the market structure of local banking industry. However, due to the difficulty in establishing proper policy counterfactuals, none of the above papers provides a causal estimate of the effects of collateral-based monetary policy on the financial market and the real economy. Our paper aims to fill in the gaps.

\section{Institutional Background}

\subsection{Bond Markets in China}

Before we elaborate on the collateral-based monetary policy in China, it is necessary to get an overview of the unique institutional setting of Chinese bond markets 7 In China, there are two parallel bond markets: the interbank market, and the exchange market. The interbank bond market, established in 1997, is an over-the-counter (OTC) bond market, and is similar to the U.S. interbank bond market. In contrast, the exchange bond market, established in 1990, is a centralized market as part of Shanghai and Shenzhen Stock Exchanges.

Participants. The participants in two bond markets vary, but they overlap in most of the nonbank institutional investors. The interbank bond market is a wholesale market, where participants are qualified institutional investors including commercial banks, mutual funds, insurance companies and security firms. The exchange-based bond market is a retail market, where non-bank institutions, corporate investors, and retail investors are allowed to invest in bonds. Commercial banks' presence in the exchange market is negligible because they are prohibited from repo transactions. Many nonbanks institutions, such as mutual funds and insurance companies, are active in both markets. The fact that commercial banks are for the most part operating only in the interbank bond market is important because, together with the fact that the participants of MLF are "commercial banks and policy banks that are subject to the macro prudential regulations," it implies that the collateralbased monetary policy tools such as the MLF are then closely linked to the interbank market, not the exchange market 8

Bond Products. Bonds traded in the exchange market on average tend to be smaller in size than those traded in the interbank market; nevertheless, many bond products in some categories, mainly enterprise bonds and government bonds, are traded in both markets. Enterprise bonds

7 Amstad and $\mathrm{He}$ (2019) provide an excellent description of the historical and institutional background of the Chinese bond markets.

${ }^{8}$ see the announcement by the PBOC regarding the establishment of MLF on September 2014: http://www.pbc.gov.cn/zhengcehuobisi 
are corporate bonds issued by state-owned enterprises, or enterprises with a high share of state holdings. Before 2005, investors in the exchange market had no access to enterprise bonds. In 2005, the National Development and Reform Commission (NDRC) in China granted non-pubic-listed state-owned enterprises access to the exchange market. Since 2005, the dual-listed enterprise bonds have been growing rapidly. In 2018, over $28 \%$ of the enterprise bonds outstanding are dual-listed. In our full data sample, $21.42 \%$ of the bond-day transactions observations are from dual-listed bonds. These dual-listed bonds will play an important role in our identification strategy.

Regulators and Clearing Houses. The two markets have different regulators. The main regulator of the interbank bond market is People's Bank of China (PBOC), China's central bank. The regulator of the exchange market is China Securities Regulatory Commission (CSRC) $!^{9}$

In the interbank market, participants trade via China Foreign Exchange Trade System (CFETS). The clearing service is provided by Shanghai Clearing House (SHCH) and China Central Depository \& Clearing Co. Ltd (CCDC). The custodial service is provided exclusively by CCDC. In contrast, in the exchange market, all bids from investors are aggregated in electronic order books, with the exchange acting as the central clearing house, and all matched trades are settled via China Securities Depository \& Clearing Co. Ltd (CSDC).

Repo Transactions and Pledgeable Collaterals. The lion's share in both markets is repurchase agreement (Repo) transactions, where a lender provides cash to a borrower, with the loan secured by the collateral from the borrower, typically bonds. The estimated repo transactions take up over $85 \%$ of the total volume in the interbank bond market, and the rest are unsecured lending between banks.

The mechanisms of repo transactions in two markets differ greatly. In the exchange market, the Exchange (the CSDC) facilitates and acts as the central counterparty for all repo transactions. The eligible collateral pool and the daily haircut rates of the collateral for repo transaction are both determined by the CSDC unilaterally. Specifically, the repo transaction accepts only AAA rated bonds as collateral in 2018, 10

In the interbank bond market, prior to October 16, 2018, the seller and buyer can bargain over the terms in the contract, including the required collateral, haircut rate and repo rate, until agreement is reached. The haircut rate and repo rate are customized according to the underlying risk of the collateral and the trading parties. Conversations with practitioners reveal that both AAA and AA+ bonds are popular collaterals in interbank market. After October 16, 2018, the China's

\footnotetext{
${ }^{9}$ The regulatory functions of CSRC are similar to that of the Securities and Exchange Commission in the United States.

${ }^{10}$ For example, in Section 2 when we discuss Chen et al. (2018) and Wang and Xu (2019), we mentioned that the CSDC suspended the eligibility of the AA+ or AA-rated enterprise bonds as pledgeable collaterals for repo transactions in the exchange market on December 8, 2014, and that on April 7, 2017, the CSDC further restricted the required minimum rating for repo collateral so that corporate bonds issued after April 7, 2017 should be rated at least AAA in order to be collateral eligible.
} 
Central Depository \& Clearing Co. Ltd (CCDC) can serve as the tri-party agent to determine the eligibility and valuation of the collateral, while the sellers and buyers only need to negotiate the borrowing amount, the maturity period and the interest rate.

Although borrowing bond for the purpose of short-selling is allowed in the interbank bond market, it is very limited ${ }^{11}$ Borrowing cost is high due to the regulation. In addition, once the value of the bonds an institution borrowed exceeds $30 \%$ of its total holdings, or the amount of a bond being borrowed exceeds $15 \%$ of its total issuance, it has to be reported to CFETS and CCDC.12 Such feature is crucial to our analysis as the cost of borrowing bonds prevents the investors from short-selling.

The difference in the mechanisms of repo transactions in the two markets results in different collateral value of the same bond across the two parallel markets.

Market Segmentation. Even though traders and products overlap in the interbank market and the exchange market, the two bond markets are largely segmented because specific rules make arbitrage between two markets very difficult. As a result, the different collateral requirements for repo purchases can result in substantial wedges in the prices of the same bond - if dual listed - in the two markets 13

There are several barriers to arbitrage between the two markets. First, According to Chen et al. (2018), in 2014 it took about three to four working days if investors apply for the transfer of depository from the interbank market (the CCDC) to the exchange (the CSDC); and it took even longer (about four to six working days in 2014) to move depository from the exchange to the interbank. The transfer of depository becomes quicker in recent years, but still takes a few days. Second, transferring money from the exchange market to the interbank market is also subject to the settlement delays. The interbank market adopts " $\mathrm{T}+0$ " settlement, while the exchange market adopts "T+1" settlement. As a result, for an investor who wants to transfer deposit from the exchange market to the interbank market, he or she would have to wait for a day. Transferring deposit from the interbank market to the exchange market also takes time. If the transaction is consummated in the interbank market in the morning, the settlement is usually completed in the afternoon. Because the exchange market closes at 3:00 pm in the afternoon, the same-day arbitrage across the two markets is therefore almost impossible to implement. Third, the settlement fee is relatively high compared to the potential gains from cross-market arbitrages. If the investor uses 100 million yuan to arbitrage for 50 bps spread, the gain would be around 1,300 yuan without considering the settlement delay, while the estimated settlement fee is 170-250 yuan. Compared to other strategies, the cross-market arbitrage seems not a very profitable option for the investors. As a result

\footnotetext{
${ }^{11}$ In 2018 , the total bond lending transaction is 2.4009 trillion yuan, the spot transaction is 151.50 trillion yuan, and the total repo transaction in the same year is 986.12 trillion yuan. See CCDC 2018 China Bond Market Report file: https://www.chinabond.com.cn/cb/cn/yjfx/zzfx/nb/20190117/150727538.shtml

${ }^{12}$ See People's Bank of China Announcement [2006] No. 15. https://www.chinabond.com.cn/Info/998422

${ }^{13}$ We provide statistical evidence in the price discrepancies of the same bond in the two markets in Section 4.3 .
} 
of these barriers, we can treat the two bond markets as more or less segmented, with potentially sustained price differences across the two markets even for the same bonds. The segmented nature of the two markets play a crucial role in our identification strategy to estimate the causal impact of collateral-based monetary policy.

\subsection{Collateral-based Monetary Policy in China}

In this paper we analyze the collateral channel of monetary policy using the following unexpected policy shock: On June 1, 2018, China's Central Bank, the People's Bank of China (PBOC), expanded the types of collateral it would allow primary dealers (commercial and policy banks) to use to borrow from its Medium-term Lending Facility (MLF) ${ }^{14}$ Launched in September 2014, MLF is a facility managed by PBOC that offers lending to commercial banks and policy banks with eligible collaterals for 3/6/12 months. An important feature of the MLF is that it only accepts targeted bonds listed in interbank market as collateral, rather than the same kind of bonds in the exchange market 15

Before the June 1, 2018 expansion of eligible collaterals, MLF accepts Treasury bonds, central bank bills, policy bank financial bonds, municipal bonds and AAA corporate bonds as collateral. The expansion will enable (1) corporate bonds; (2) bonds issued by small and micro firms (Xiaowei Bonds); (3) bonds to support green economy (Green Bonds); and (4) financial bonds serving agriculture and rural areas (Sannong Bonds) rated at least AA to be used as collateral for MLF 16 17 The total amount of newly pledgeable bonds for MLF was between 400-600 billion yuan (about $\$ 80$ billion). The PBOC claimed that the move is aimed at lowering the funding costs and enhancing the support to smaller businesses.

\section{[Table 1 About Here]}

It is not the first time for PBOC to use collateral-based monetary policy. Table 1 illustrates the collateral-based monetary policy tools that the PBOC launched prior to 2018. In January 2013, PBOC launched Short-term Liquidity Operation (SLO) and Standing Lending Facility (SLF), providing liquidity to primary dealer banks with maturity of less than 7 days and between 1 to 3 months, respectively, backed by high quality assets. In 2014, PBOC shifted to longer term collateral-based monetary policy: Pledged Supplementary Lending (PSL) in April 2014, and MLF

\footnotetext{
${ }^{14}$ See PBOC's announcement of the policy change on June 1, 2018 at http://www.pbc.gov.cn/zhengcehuobisi.

${ }^{15}$ As discussed in the previous subsection, transferring depository from the exchange to the interbank market is time consuming and costly.

${ }^{16}$ In Chinese, "Xiaowei" means "small or micro firms"; "Sannong" is the short cut for "three things related to rural issues: peasants, agriculture, and rural areas."

${ }^{17}$ In China, the corporate bonds include exchanged-traded corporate bonds, enterprise bonds, medium term notes and commercial paper. We focus on the first three types of bonds. The commercial paper usually has less than 1-year maturity and therefore is not popular collateral for MLF. Financial bonds are bonds issued by financial institutions, including commercial banks, insurance companies, and security firms.
} 
in September 2014, respectively. The last row of Table 1 lists the eligible collaterals for each lending facility as of 2018 .

\section{[ Figure 1 About Here]}

The collateral-based lending facilities have gained increasing significance in PBOC's monetary policy since 2014. Figure 1 depicts the growing size of lending through SLF, MLF and PSL by PBOC during the period of March 2013 and January 2019 ${ }^{18}$ It is interesting to note that, although these unconventional monetary policy tools were only introduced between 2013 and 2014, they experienced rapid growth since their launches. At the end of 2018, the balance of MLF, SLF and PSL accounted for about $25 \%$ of China's monetary base, as is shown in Figure 1. This is especially significant for MLF, which is the largest and most important component of PBOC's collateral-based lending facilities.

\section{[ Figure 2 About Here]}

Shifting from traditional monetary policy to unconventional monetary policy changes the way China's Central Bank provides liquidity. Figure 2 illustrates the liquidity transmission mechanism of traditional and collateral-based monetary policy. In the traditional liquidity transmission mechanism, the Central Bank influences the broad financing conditions in the economy by steering the interbank rate. In the unconventional liquidity transmission system, the Central Bank decides not only the interest rates but also the eligible collaterals for the SLF, MLF or PSL lending facilities. By accepting the relatively illiquid assets as collaterals, China's Central Bank provides liquidity to the primary commercial banks. The liquidity is then transmitted through repo transactions from the primary dealer banks to other non-bank financial institutions in the interbank market, and in turn, these financial institutions provide liquidity to the real economy.

Theoretically at least, the collateral-based monetary policy tools offer the Central Bank more flexibility than the traditional interest rate policies when the policy goals include lowering the borrowing cost of some targeted sectors. Take MLF as an example. In the expansion of eligible MLF collaterals on June 1, 2018, PBOC made corporate bonds and financial bonds of Xiaowei firms, Green firm and Sannong firms with at least AA ratings to be eligible collaterals, which lowered the spreads of these bonds in secondary market, as we will show in Section 4. This, theoretically, would in turn further decrease the coupon rate of these bonds in primary market.19 If working effectively, MLF would ease the funding constraints for commercial banks that support small firms, environmental protection and agriculture. We will indeed provide evidence of the primary market reactions in Section 5 .

\footnotetext{
${ }^{18}$ Since the lending period of SLF is less than 3 months, as shown in Table 1 , the quarterly balance is actually not very good indicator of its size. The lending period of SLO is even shorter, of less than 7 days. We do not have quarterly balance data on SLO.

${ }^{19}$ In China, the coupon rate of bonds is determined through a tender process on "tender day", 3 trading days before the bond is listed in the market.
} 
China is not alone in adopting unconventional monetary policy tools. The MLF resembles the first three rounds of long-term refinancing operations (LTROs) by the European Central Bank in the Eurozone, with 6-month to 1-year maturity. ${ }^{20}$ The U.S. has also launched Term-Asset Security in March 2019. Under the TALF, the Federal Reserve Bank of New York (FRBNY) loaned up to $\$ 200$ billion on a non-recourse basis to holders of certain AAA-rated ABS backed by newly and recently originated consumer and small business loans. ${ }^{21}$ Although the collateral-based monetary policy tools adopted in China and many other countries have been theoretically predicted to be useful, empirical test of the effectiveness of these unconventional monetary policies is not easy. As these policies are always concurrent with other monetary policies and financial regulations, and are endogenous to underlying macroeconomic conditions, it is difficult to isolate the causal impact of these collateral-based monetary policies from other confounding factors.

The unique coexistence and the segmentation of the interbank bond market and the exchange bond market in China offers us a rare opportunity to identify the causal impact of the collateralbased monetary policy using a clear identification strategy. As the policy shock of June 1, 2018 only applies to bonds in the interbank market, and the disparate regulations of and the barriers between the two bond markets effectively prevent the investors from arbitraging, we are able to isolate the causal impact of the collateral-based monetary policy. By comparing the changes, before and after the policy shock, in the difference of spreads of the newly collateral-eligible bonds (the treatment bonds) and other bonds (the control bonds) in the two markets, we are able to identify the causal effects of the collateral-based monetary policy on the financial market. In addition, we are able to examine the transmission of the monetary policy operations in the secondary market to the primary market, and thus the impact on the real economy. In other words, we will provide causal empirical evidence of the transmission mechanisms of the unconventional collateral-based monetary policy as depicted in Figure 2 .

\section{Secondary Market: Data, Methods and Results}

In this section, we describe the data, methods and results on the impact of the policy shock on the secondary market bond pricing. We also provide empirical evidence for the segmentation of the interbank and the exchange markets, which is essential for our empirical strategy.

\subsection{Data}

Sample Selection As the June 1, 2018 policy shock was mainly targeted at corporate bonds and a subset of the financial bonds, we restrict our analysis sample to only corporate bonds and financial bonds. We obtain the bond characteristics, including credit ratings and issuers, and daily

\footnotetext{
${ }^{20}$ In the fourth round, the ECB launched three-year maturity LTROs https://www.ecb.europa.eu/mopo/ implement/omo/html/index.en.html

${ }^{21}$ For a description of TALF, see https://www.federalreserve.gov/monetarypolicy/talf.htm
} 
bond transaction information, including yield-to-maturity, trade volume, close price, etc. from WIND 22

Our sample period is from $1 / 1 / 2018$ to $09 / 30 / 2018$, with 5 -month window (99 trading days) before the June 1, 2018 policy shock and 4-month window (83 trading days) after the policy shock, respectively. If a bond does not have any trading in a particular day, we will code the bond's observation as missing for that day. We follow Schwert (2017) to exclude observations of bonds with less than 1 year to maturity, because at such a short maturity small price changes can lead to large deviations in the implied yield. We further restrict the bonds to those issued before 09/01/2017, because newly issued bonds tend to exhibit high markups.

We also restrict our analysis sample to bonds with AA or higher ratings. Bonds rated under AA account for only a small proportion (less than 5\%) of our sample, and such bonds are considered risky in China; we thus exclude bonds with lower than AA ratings in order to eliminate the potential noise from these risky bonds 23

For part of the analysis, we will further restrict our sample to bonds that are dual-listed in both the interbank and the exchange market. A dual-listed bond has the advantages of being able to be matched to itself in the other market, and by definition the matched pair have the same fundamentals.

Construction of Spread. The main dependent variable of our analysis is the spread of the bonds, which is calculated as the difference between the yield (to maturity) of bonds and the yield of ChinaBond Government Bond (CGB) with the same term to maturity on the same day. ${ }^{24}$ The yield to maturity for the bonds in the exchange market is obtained from WIND, and the yield to maturity for bonds in the interbank market is calculated by CFETS. Both calculations are based on the secondary market transaction prices ${ }^{25}{ }^{26}$

We take the targeted bonds, i.e., the bonds in the interbank market that are newly eligible as collaterals for MLF as described in Section 3.2, as treatment bonds in the treatment market, and the same type of bonds in the exchange market as treatment bonds in the control market. Similarly, we consider other bonds that are not impacted by the 06/01/2018 policy shock as control bonds in the treatment market and control bonds in the control market, respectively. The control bonds include AAA-rated bonds, and financial bonds that are not in the targeted sectors.

\footnotetext{
${ }^{22}$ WIND is a major financial data provider for China.

${ }^{23}$ In 2018, many bonds rated under AA defaulted.

${ }^{24}$ The yield curve of ChinaBond Government Bond is provided by CCDC. http://yield.chinabond.com.cn/ cbweb-pbc-web/pbc/more?locale=en_US

${ }^{25}$ WIND calculates the bond yield of a given day, if there are transactions on the exchange market, based on a volume-weighted transaction price, inclusive of the interest income of the day. See p.19 of http://net.wind.com.cn/WindNET/Bulletin/page/windnet3.htm. CFETS calculates the bond yield of a given day similarly, but with an extra step of estimating a yield-curve predicted yield of the bond, then adjusted using the day's transaction prices and volumes. See http://www.chinamoney.com.cn/.

${ }^{26}$ Individual and mutual funds pay income tax of $20 \%$ on all interest incomes, and the tax rate does not vary by bonds, duration of holding, and the bond market.
} 


\section{[ Figures 344 About Here]}

Figure 3 provides suggestive evidence that the policy shock reduces the spreads of the treatment bonds in the interbank market. Figure 3 a compares the average daily spreads for all corporate and financial bonds in the two markets by ratings before (the left panel) and after (the right panel) the policy shock. Both panels show that, for a given bond rating, the average daily spreads are lower in the interbank market than in the exchange market. The difference in the spreads is most significant for AA rated bonds, followed by AA+ rated bonds, and it is the smallest for AAA rated bonds. However, following the policy shock, the difference in spreads between the two markets of AA and $\mathrm{AA}+$ rated bonds - where include all the treatment bonds - increased drastically, while the spread difference of AAA rated bonds only increased marginally. In Figure $3 \mathrm{~b}$, we restrict the sample to dual-listed bonds only. As we mentioned in Section 3.1, dual-listed bonds are all enterprise bonds, therefore the AA+ and AA rated dual-listed bonds are almost all treatment bonds, and the AAA bonds are all control bonds which were already collateral eligible for MLF prior to the June 1, 2018 policy shock. Figure $3 \mathrm{~b}$ reaffirms the same qualitative effect as that from Figure $3 \mathrm{a}$ : After the policy shock, the treatment bonds (AA+ and AA rated bonds) experienced somewhat larger decreases in spreads than the control bonds (AAA rated bonds).

Figure 4 further shows the daily movements of the spread differences between the interbank and the exchange market, by bond ratings, before and after the policy shock. The shaded area is a 5-trading day period since the expansion of the eligible collaterals for MLF. Figure 4 suggests that in the 5-day window, the spreads of AA and AA+ rated bonds (treatment bonds) in interbank market (the treatment market) falls relative to that in exchange market (the control market), while at the same time, the spread differences between the two markets for AAA bonds (control bonds) somewhat increased. Figures 344 both suggest that the expansion of MLF eligible collateral to include corporate bonds and some financial bonds rated AA+ or AA may have causally increased the prices, and thus decreased the spread, of these targeted bonds in the secondary market.

\subsection{Descriptive Statistics}

[Table 2 About Here]

In Table 2, we provide the summary statistics for all corporate and financial bonds in the secondary market with AA or higher ratings. Recall that our sample restrictions exclude the very small percentage of bonds with below AA ratings. In Panels A-C, an observation is a bond-day. In the columns headed by "Full Sample", we include all bond-day observations (a total of 78,592). We also provide summary statistics for bond-day observations in the interbank market (a total of 35,406 , about $45 \%$ of the total observations) and the exchange market (a total of 43,186 , about $55 \%$ of the total observations) separately. Panel A shows that the average daily spread is $3.123 \%$ in the full sample, and the average daily spreads are $2.547 \%$ and $3.594 \%$ in the interbank market and the exchange market, respectively. In the full sample, about $42 \%$ of the bond-day observations are after 
the June 1, 2018 policy shock (Post $=1$ ); separately by market, the post-shock observations account for $40.4 \%$ and $43.3 \%$ respectively in the interbank and exchange market. In the full sample, $59.5 \%$ of the observations are those of the treatment bonds (Treat $=1$ ); the corresponding percentages are $54.8 \%$ and $63.4 \%$ in the interbank and the exchange market, respectively. The maturity to term averages 2.955 years in the overall sample; and it is 3.069 and 2.861 years, respectively, in the interbank and the exchange market. As expected, the average daily volume of trade is much larger in the interbank market (115.8 million yuan) than in the exchange market (8.443 million yuan).

In Panels $\mathrm{B}$ and $\mathrm{C}$ of Table 2, we report the summary statistics of bond ratings and bond types, respectively. Panel $\mathrm{B}$ shows that AAA rated bonds account for $40 \%$ of the observations in the overall secondary market, and about $44.1 \%$ and $36.3 \%$ in the interbank and the exchange market respectively. The percentages of $\mathrm{AA}+$ and $\mathrm{AA}$ rated bond-day observations are both somewhat smaller in the interbank market than in the exchange market. Panel $\mathrm{C}$ shows that about $33.4 \%$ of observations are those of exchange-traded corporate bonds, which by definition do not appear in the interbank market transactions. Similarly, a type of corporate bonds, known as medium-term notes, are only traded in the interbank market. Observations of enterprise bonds (which are corporate bonds for large State-owned enterprises) account for about $36.2 \%$ of the total observations, and they appear in both the interbank market and the exchange market. As we will show in Table 3 , indeed all dual-listed bonds are enterprise bonds. Financial bonds appear in both markets, but they account for only a relatively small fraction of all the observations.

In Panel D of Table 2, we summarize the data at the unique bond level. It shows that in total there are a total of 6,057 unique bonds in the full sample, of which 5,650 of them are corporate bonds of various kinds - including 1,880 enterprise bonds, 1,447 exchange-traded corporate bonds, and 2,323 medium-term notes; and only 407 are financial bonds. Note that the medium-term notes are only traded in the interbank market, and the exchange-traded corporate bonds are only traded in the exchange market. There are a total of 526 enterprise bonds that are dual-listed in both markets.

\section{[Table 3 About Here]}

In Table 3, we provide the summary statistics, focusing on the dual-listed bonds only. First of all, as shown in Panel C of Table 2, only enterprise bonds are dual listed. Moreover, of the 28,460 bond-day observations of enterprise bonds listed in Panel $\mathrm{C}$ of Table 2, 16,831 of them are those of dual listed enterprise bonds. Thus, about $60 \%$ bond-day transactions of all enterprise bonds are those of dual listed bonds. At the unique bond level, Panel D of Table 3 shows that 526 out of the 1,880 , namely, about $28 \%$, of the enterprise bonds are dual listed and have transactions in both market during our sample period.

Panel A of Table 3 shows that the basic patterns of the spread differences between the interbank market and the exchange market for all bonds hold for dual-listed bonds as well. For example, the average spread tends to be lower in the interbank market than in the exchange market $(2.612 \%$ vs. $3.696 \%$ ). About $42 \%$ of the bond-day observations are post policy shock (Post $=1$ ), and about 
$76.5 \%$ of the bond-day observations are those of the treatment bonds (Treat $=1$ ). At the bond-day observation level, dual-listed enterprise bonds tend to have shorter term-to-maturity than non-dual listed bonds: the average term-to-maturity for dual listed bonds is 2.852 years, in contrast to 2.955 years for all bonds as reported in Panel A of Table 2. Comparing Panel B of Tables 2 and 3 reveals that there are much smaller fraction of AAA rated bond-day observations among dual listed bonds than among all bonds.

\subsection{Evidence for Market Segmentation}

[Table 4 About Here]

An important institutional feature of the parallel bond markets in China that is crucial for our empirical approach is that the interbank market and the exchange market are effectively segmented, despite the fact that there are many dual listed bonds and that many market participants trade in both markets. In Section 3, we provided the detailed information about the barriers to crossmarket arbitrage. In this subsection, we provide further evidence about the spread discrepancies between the two markets for dual listed bonds when there were "simultaneous transactions" in the two markets. Our definition of "simultaneous transactions" is close to that in Chen et al. (2018). For any transaction of a dual-listed bond in the interbank market at a particular date, say date $t$, the "simultaneous transactions" in the exchange market are transactions of the same bond on trading days between $t-2$ and $t+2$. We then calculate the spread difference between the trades in the interbank market and their closest corresponding "simultaneous transactions" in the exchange. We are able to construct 1,089 such matched pairs in our sample.

Panel A of Table 4 shows that the mean absolute difference of the matched trades is $109.2 \mathrm{bps}$, with the minimum difference of 0.0185 bps and the maximum difference 1166 bps. In Panel B, only slightly more than 10 percent of all the matched trades have absolute spread differences of less than 5 bps; and more than 36 percent of the matched trades differ in spread exceeding 100 bps!

[Figure 5 About Here]

Figure 5 presents the kernel density plot of the absolute spread difference of dual-listed bond trades in the interbank market and the "simultaneous transactions" of the same bond in the exchange market. It shows that the distribution has significant probability mass on absolute spread differences exceeding more than 30 bps.

The large absolute spread differences between matched trades in the two markets provide direct empirical evidence that the two markets are effectively segmented. This is crucial because the segmentation allows us to interpret the exchange market as the "control market" that are immune to "contamination" when the interbank market experiences the policy shock of June 1, 2018. The

availability of such a control market allows us to construct the "counterfactual outcome" of the treatment bonds in the control market. 


\subsection{Baseline Regression Specifications and Results}

Baseline Result. In order to examine whether the expansion of the MLF eligible collateral to include the treatment bonds has any impact on their spreads in the secondary market, our main estimating equation is a triple-difference (DDD) specification:

$$
\text { Spread }_{i j t}=\beta_{1} \text { Post }_{t} \times I B_{j} \times \text { Treat }_{i}+\beta_{2} \text { Post }_{t} \times \text { Treat }_{i}+\delta_{i j}+\theta_{j t}+(B R \times B T)_{i t}+\varepsilon_{i j t},
$$

where the subscripts $i, j$, and $t$ respectively denote bond $(i)$, bond market $(j)$, and the date $(t)$. The dependent variable Spread $_{i j t}$ is the yield of bond $i$ in market $j$ at date $t$ relative to the CGB bonds of the same date $t$ as we have discussed in Section 4.1. The right hand side variables are as follows:

- Post $_{t}$ is a dummy that equals to 1 if the date $t$ is after June 1,2018 , and 0 otherwise;

- Treat ${ }_{i}$ is a dummy which equals to 1 if the bond is one of the newly included bonds in the MLF eligible collateral expansion, i.e. if $i$ is one of the treatment bonds: (i) corporate bonds rated $\mathrm{AA}$ and $\mathrm{AA}+$; (ii) financial bonds rated $\mathrm{AA}, \mathrm{AA}+$ and $\mathrm{AAA}$ in the targeted "Xiaowei," "Green" and "Sannong" sectors;

- $I B_{j}$ is a dummy which equals to 1 if the bond-day observation is from the interbank market (the treatment market), and 0 otherwise.

- $\delta_{i j}$ 's are bond by market fixed effects, which absorb bond fixed effects (capturing the effects of bond characteristics such as bond type, bond ratings, bond issuance size, bond issuer, etc.), as well as $I B_{j}$, Treat $_{i}$ and $I B_{j} \times$ Treat $_{i}$, which would have appeared in a typical DDD setting.

- $\theta_{j t}$ are market by date fixed effects, which absorb the day-by-day average difference in bond spread between the two markets due to different market liquidity and institutional differences between them. Note that $\theta_{j t}$ also absorb Post $_{t} \times I B_{j}$, which would have appeared in typical DDD setting.

- $(B R \times B T)_{i t}$ are the bond rating (BR) by bond type (BT) by date fixed effects, which absorb the day-by-day average differences in bond spread for each type and each rating level of bonds. The $(B R \times B T)_{i t}$ fixed effects are not market specific, hence these fixed effects capture the fluctuations in the average spreads for each bond type and each bond rating level from common shocks affecting both markets. Also, note that $(B R \times B T)_{i t}$ fixed effects do not fully absorb the Post $_{t} \times$ Treat $_{i}$ when we use the observations from the full sample in our analysis. The reason is that only financial bonds (a particular bond type) with AA or AA+ ratings in "Xiaowei," "Green" and "Sannong" are treated. Thus we also include Post ${ }_{t} \times$ Treat $_{i}$ in the regression when using the full sample 27

\footnotetext{
${ }^{27}$ When restricting ourselves to dual-listed bonds, the term Post $_{t} \times$ Treat $_{i}$ will be dropped because financial bonds are never dual listed.
} 
- $\varepsilon_{i j t}$ are the bond-market-day specific errors, which we allow for correlations at the bond level, but independent across date $t$ and market $j$.

In estimating regression equation (1), $\beta_{1}$ is our main parameter of interest. It captures the average changes in spread between the treatment bonds and the control bonds after the treatment bonds were included as eligible collateral for MLF in the interbank market, ceteris paribus, where we proxy for the potentially differentially effects of time-varying macro shocks on the treatment and control bonds by the spread movements in the exchange market (the control market). We expect $\beta_{1}$ to be negative, as predicted by the leverage cycle theory: as the treatment bonds in the interbank market acquire collateral values after the MLF expansion, their spreads relative to the control bonds should decrease, ceteris paribus.

\section{[Table 5 About Here]}

Table 5 reports the results from the baseline regression as specified by equation (1). Column (1) uses the full sample of bond-day transactions as summarized in Table 2, and Column (2) uses only the bond-day transactions of the dual-listed bonds as summarized in Table 3. Recall that, when we use the dual-listed bond-day transactions, the Post $_{t} \times$ Treat $_{i}$ interaction is subsumed by the Bond Type x Bond Rating x Date fixed effects.

Column (1) shows that the $\beta_{1}$ coefficient estimate of the triple interaction term Post $\times$ Treat $\times I B$ is -0.618 and statistically significant at $1 \%$ level. That is, the spread difference between the treated bonds and the control bonds are reduced by 61.8 bps in the (treated) interbank market relative to the (control) exchange market after the treated bonds were made eligible as collateral for MLF. Note also that the coefficient estimate of the Post $\times$ Treat is positive and significant, suggesting the importance of allowing for the possibility of the treated bonds and control bonds to be differentially impacted by other macro shocks, which we do by using the exchange market as the control market. In Column (2), we use only the matched dual-listed bond-day transactions in the regression. Importantly, we find that the coefficient estimate of the triple interaction is qualitatively and quantitatively consistent with that of Column (1): the expansion of MLF collateral decreases the relative spread of treatment bonds by about $42 \mathrm{bps}$, though because of the smaller sample size, the statistical significance of the estimate is now at the $10 \%$ level.

Spillover Effect to Other Bonds in the Interbank Market. We also investigate whether impact of the policy shock is restricted to the treated bonds, or it can impact the spreads of all bonds in the (treated) interbank market. For example, Ashcraft et al. (2011) points out that, if the haircut rates of a subset of securities are sufficiently reduced, the supply of collateral in the market will increase substantially, which leads to an easing of investors' funding constraint, and in turn decreases the spread of other securities even though their haircut rates are not directly impacted. In other words, collateral-based monetary policy tools can possibly result in positive spillover effects from the treated bonds to the control bonds in the treatment market, leading to overall lower average spreads in interbank bond market. 
To test whether the MLF collateral expansion has a spillover effect on the spreads of bonds traded in the interbank market as a whole, we use the following regression specification: ${ }^{28}$

$$
\text { Spread }_{i j t}=\gamma_{1} \text { Post }_{t} \times I B_{j}+\gamma_{2} \text { Post }_{t} \times I B_{j} \times \text { Treat }_{i}+\delta_{i j}+(B R \times B T)_{i t}+\varepsilon_{i j t}
$$

where $\gamma_{1}$ captures the average policy effect on the spreads of bonds in interbank market. $\gamma_{1}$ is expected to be negative if the MLF collateral expansion has effectively reduced the spreads of other non-treated bonds in interbank market.

\section{[Table 6 About Here]}

Table 6 reports the results. In Column 1 where the full sample is used in the regression, the coefficient estimate of the interaction term Post ${ }_{t} \times I B_{i}$ is negative 10.4 bps but it is not statistically significant; however, in Column 2 where we use the dual-listed bonds only, we find that indeed the policy shock reduced the overall spreads of the dual-listed bonds in the interbank market relative to those in the exchange market, even for the bonds that are not directly treated. The magnitude of the spillover effect is also quite substantial: the average spread of dual listed bonds is reduced by 34.3 bps even if they were not treatment bonds, and this effect is statistically significant at $10 \%$ level. Thus the results reported in Table 6 provides some evidence for the predictions from model of Ashcraft et al. (2011) that a higher supply of collateral in the interbank market eases the overall funding constraints in the treatment market and lowers the overall spreads, with the caveat that the spillover effect seems to be restricted to dual listed bonds only.

\subsection{Additional Analysis}

Parallel Trends. A requirement for DDD as specified by Equation (1) as a valid identification strategy is that the difference in the spreads between treated and control bonds in the interbank market (the treatment market) and those in the exchange market (the control market) exhibit parallel trend prior to the policy shock. In this subsection, we conduct the parallel trend analysis. The model is specified in Equation (3):

$$
\text { Spread }_{i j t}=\sum_{k=-20, k \neq 0}^{k=17} \alpha_{k} D_{t}^{k} \times I B_{j} \times \text { Treat }_{i}+\beta_{1} \text { Post }_{t} \times \text { Treat }_{i}+\delta_{i j}+(B R \times B T)_{i t}+\theta_{j t}+\varepsilon_{i j t}
$$

where we divide our sample period (a total of 184 trading days) into 36 sub-periods, with each period consisting of a 5-day window. The dummies $D_{t}^{k}$ equals 1 if the date $t$ falls in the sub-period $k$, and 0 otherwise. Following Freyaldenhoven et al. (2019), we normalize the point estimate of the DDD coefficient immediately before the policy shock date to zero. The same sets of control variables as those specified for regression specification (1) are included.

\footnotetext{
${ }^{28}$ Note that the fixed effects $\theta_{j t}$ are not included in equation $\sqrt{2}$ because it is collinear with Post $_{t} \times I B_{j}$.
} 
[Figure 6 About Here]

Figure 6 plots the point estimate of $\alpha_{k}, k \in\{-20, \ldots-1,1, \ldots, 17\}$ and the corresponding $95 \%$ confidence intervals. Panel A of Figure 6 suggests that, the spread differences between the (later) treated bonds and the control bonds in the interbank market parallel those in the exchange market before the the collateral expansion policy took effect on June 1, 2018. However, after the expansion of the set of eligible collateral for MLF, the spread difference of the treated bonds and the control bonds significantly decreased in the interbank market relative to that in the exchange market. The magnitude reaches close to 100 bps about 30 trading days after the policy shock. The negative impact on the spreads for treated bonds persists for over 60 trading days. Panel B of Figure 6 shows the pattern of $\alpha_{k}$ estimated when we use only the transactions of the dual-listed bonds is similar, with slightly larger magnitudes.

Liquidity vs. Default Spreads We interpret the negative coefficient of $\beta_{1}$ reported in Table 5 as evidence of the working of the collateral channel. One may be concerned, however, that the expansion of MLF collateral may increase the market liquidity of the targeted bonds, therefore decreases the spread of targeted bonds without necessarily changing their collateral values. For example, it is possible that the policy changes the distribution of investors' belief and increases the frequency of transactions of the targeted bonds and increase their market liquidity. To interpret the findings in Table 5 as the evidence of collateral channel, it is crucial for us to distinguish between the policy impact on liquidity spread and default spread.

To this end, we follow Schwert (2017) to decompose the spread into liquidity spread and default spread as follows. First, we construct the illiquidity measure in the existing finance literature proposed by Amihud (2002). The illiquidity measure, which we denote by Amihud, for bond $i$ in market $j$ at time $t$ is based on the absolute daily return relative to the trading volume, averaged over a seven-trading-day window around the focal date. Specifically ${ }^{29}$

$$
\text { Amihud }_{i j t}=\frac{1}{7} \sum_{s=t-3}^{t+3} \frac{\left|r_{i j s}\right|}{V o l_{i j s}}
$$

where $\left|r_{i j s}\right|=\frac{\left|P_{i j s}-P_{i j s-1}\right|}{\left|P_{i j s-1}\right|}$ is the absolute daily return constructed using $P_{i j s}$, the clean close price for bond $i$ in bond market $j$ on date $s$; and $V o l_{i j s}$ is the trading volume of bond $i$ in market $j$ on day $s$, where $s$ are the seven-trading-days around the focal date $t$. The higher is Amihud $_{i j t}$, the lower is the liquidity of bond $i$ in market $j$ at date $t$ because more liquid bonds are likely associated with larger trading volumes and less day-to-day price volatility.

Second, with the illiquidity measure constructed by (4), we follow Schwert (2017) to decompose the yield spread of a bond into a liquidity spread and a default spread. In order to construct the liquidity spread, we run, separately by quarter $q \in\{1,2,3\}$ and by market $j$, the following set of

\footnotetext{
${ }^{29} \mathrm{As}$ bond transactions are not frequent, we take a weekly moving average to calculate $A m i h u d_{i j t}$.
} 
regressions:

$$
\text { Spread }_{i j t}=\alpha_{q j} \text { Amihud }_{i j t}+\boldsymbol{\beta}_{q j} \mathbf{X}_{i j t}+B R_{i j}+\theta_{t}+\varepsilon_{i t}, \text { if } t \in \mathcal{D}_{q}
$$

where Amihud $_{i j t}$ is the illiquidity measure constructed in (5), $\mathbf{X}_{i j t}$ refers to a set of bond characteristics such as issuance size, term to maturity, bond coupon rate, $B R_{i j}$ is the bond rating fixed effect, $\theta_{t}$ is the trading day fixed effect, and $\mathcal{D}_{q}$ denotes the trading days in quarter $q \in\{1,2,3\}{ }^{30}$ By running the regressions of equation (5) separately for each quarter and each market, we generate $\hat{\alpha_{q j}}$. In addition, for each market $j$, we denote the 1st percentile of the distribution of computed Amihud $_{i j t}$ as $A m i h u d_{1 p j}$, and use it to benchmark the illiquidity measure of a very liquid bond in market $j$.

Now we follow Schwert (2017), and decompose the spread of bond $i$ in market $j$ at date $t$ into liquidity spread and default spread; specifically, the liquidity spread of bond $i$ in market $j$ at date $t$ is calculated as:

$$
\text { LiquiditySpread }_{i j t}=\widehat{\alpha_{q j}}\left(\text { Amihud }_{i j t}-\text { Amihud }_{1 p j}\right) \text {; }
$$

and its default spread is simply the residual of its spread after subtracting the liquidity spread estimated in (6):

$$
\text { DefaultSpread }_{i j t}=\text { Spread }_{i j t}-\text { LiquiditySpread }_{i j t} .
$$

We then regress the liquidity spread and default spread constructed above as the dependent variable, and run the baseline regression as specified in (1). The results are reported in Table 7 . The left panel uses the full sample and the right panel only the dual listed bond transactions. Columns (1) and (4) simply replicate the results in Table 5. Columns (2) and (5) report the results for liquidity spread, Columns (3) and (6) for the default spread. Column (2) shows that the coefficient estimate of the triple interaction term Post $\times$ Treat $\times$ IB is positive and statistically significant, suggesting that the treated bonds may have actually experienced an increase in the liquidity spread in the interbank market after the policy shock. This is theoretically possible, for example, if a large quantity of treatment bonds is used as collateral for MLF, which reduces the available of such bonds for transactions in the interbank market. However, when we restrict to the dual listed bonds only, we find in Column (5) that the causal impact of the MLF collateral expansion has almost no effect on the liquidity spread of the treated bonds in the interbank market. In contrast, we find that the coefficient estimates of the triple interaction term Post $\times$ Treat $\times$ IB are almost identical to those of Column (1) and (4) for the total spread. Thus we conclude that almost all the decrease of the total spread is due to the decrease of the default spread, and the liquidity spread is not significantly affected by the expansion of the MLF collateral 31 This is consistent with the prediction of the leverage cycle theory that leverage allows more optimistic investors to incorporate their opinions into the spread, and their perceived default risk is lower.

\footnotetext{
${ }^{30}$ Recall from Section 4.1 our sample period is from $1 / 1 / 2018-8 / 31 / 2018$, which covers three quarters.

${ }^{31}$ We also examined the dynamics of the changes in liquidity spread and default spread separately using the regression specification of (3). The change in default spread almost explains all the fluctuations in the total spread due to the policy shock. Results are available from the authors upon request.
} 
[Table 7 About Here]

Heterogeneous Analysis. One of the policy objectives of PBOC's unconventional collateralbased monetary policy to include the treated bonds as MLF eligible collateral is to adjust the leverage structure of economy and free up funding for small firms (Xiaowei), green firms and agricultural (Green) firms. To examine whether the expansion of MLF collateral indeed help achieve these policy objectives, we conduct a heterogeneous analysis where we further allow Post $\times$ Treat $\times$ IB to interact with Green, Xiaowei or Sannong dummies in the baseline regression specification (1). Since the dual listed bonds do not include any financial bonds (see Table 3), such a heterogeneous analysis can be performed only using the full sample. Table 8 reports the results. We find that Xiaowei bonds seem to have experienced a particularly large spread reduction after the policy shock (additional 47.6 bps), while the estimates for the Green and Sannong bonds are quite noisy.

[Table 8 About Here]

\section{Primary Market: Data, Methods and Results}

Since the secondary market does not directly involve the financing of the bond issuers, to assess the impact of the collateral-based monetary policy on the real economy it remains to be shown whether the policy has decreased the borrowing cost of bond issuers in the primary market.

The transition of the monetary policy effect from the secondary market to the primary market relies on the fact that the tender process for new bond issuance ensures that the coupon rate is correlated with the market rate of a comparable bond in the secondary market. In China, the new corporate bond issuance is marked with several important dates: The bond issuer first has to submit an application to National Development \& Reform Commission (NDRC). The issuer usually has to wait for 2-3 months for NDRC to process the application. After the approval, the issuer can decide when and which market to issue the bonds. After the issuer has decided the time and the place, a bond prospectus is published, and a tender process is scheduled. The tender day is usually 2 trading days after the bond prospectus is issued. On the tender day, all qualified tenders participate in a uniform-price auction where they submit sealed bids of yield-quantity pairs that specify the amount they are willing to purchase at a specified minimum yield to the underwriter. The market-clearing yield, which determines the coupon rate of the bond, is the yield at which the aggregate demand submitted by all tenders equates the bond issuance amount. The bond is settled on the following day, and the bond will be traded in the secondary market on the first business day after the settlement ${ }^{32}$ The tender process ensures that a new bond's coupon rate will be closely related to that of an existing comparable bond in the secondary market. If the spreads

\footnotetext{
${ }^{32}$ See Ding et al. (2019) for a description of the bond issuance process in China. They document the bond overpricing in the primary bond market in China.
} 
of comparable bonds in the secondary market have decreased, it is likely that the coupon rate of new issuance would also decrease.

In this section, we use bond issuance data to examine whether the expansion of MLF eligible collateral resulted in lower financing cost for new bond issuers.

\subsection{Data}

Sample Selection. We focus on the issuance of corporate bonds and financial bonds. Following the logic behind the sample selection rules used in Section 4 for the secondary market, we restrict the sample to newly issued bonds rated at least AA. In baseline analysis we restrict the sample period to 1/1/2018-08/31/2018; later we also use data from 1/1/2015-08/31/2015 to conduct a placebo test. We choose to focus on the primary bond issued before 8/31/2018 because the applications for such new bond issuances almost certainly would have been submitted to the NDRC for approval before the policy shock date of June 1, 2018, because as we previously mentioned, it would typically take NDRC 2-3 months to process a new bond issuance application. We restrict our analysis to include new bonds issued after the policy date, but whose applications for approval before the policy date to avoid potential biases from firms changing their venue of bond issuance (see Section 5.3 for some evidence of firms shopping for the venue of bond issuance after August 1, 2018). It is possible that some firms would take advantage of the monetary policy and shift their bond issuance from the exchange market to the interbank market, which may result in a selection bias if bonds issued by these "mover" firms are of lower default risk or higher liquidity than bonds of the same rating issued by "non-mover" firms. Bond issuance information are obtained from WIND.

Construction of Spread. The dependent variable is spread, calculated as the difference between coupon rate and the yield of ChinaBond Government Bond (CGB) with the same term to maturity on the same day. In China, all bonds are issued at face value, therefore the yield to maturity at issuance equals the coupon rate of the bonds.

[Figures 7 and 8 About Here]

We first provide a first glance of the effect of the expansion of MLF collateral on the issuance spread of treated bonds. Figure 7 shows the monthly average bond spreads in the interbank market and the exchange market, by rating categories, as well as the difference in the average spreads in the two markets. The left graph uses data from the five months before the policy change, and the right graph uses data from the three months after the policy change. It shows that the spread is lower in the interbank market than in exchange market for all rating categories. However, comparing the left and right panel reveals that the spread difference between the interbank market and the exchange market is significantly lower for AA and AA+ rated bonds after the policy change, but there is no change in the spread difference between the two markets for AAA rated bonds. Figure 8 shows the evolution of the differences in the average spreads of bonds in the two markets before 
and after the expansion of MLF collateral by rating categories in five-day windows. The figure suggests that, before the policy change, the spread difference between the interbank market and the exchange market does not exhibit a clear trend for all three rating categories; however, after the policy change, the AA and AA+ rated bonds experienced a sharp decline in spreads in the interbank market relative to those in the exchange market; in contrast, the change for AAA rated bonds (control bonds) is smaller and does not exhibit a significant decline.

Control Variables. Because a new bond cannot be issued both before and after the policy shock, the identification strategy for the effect of the policy shock on the primary market spreads of the treated bonds must be different from that for the secondary market. To ensure that the bonds issued before the policy shock and those issued after the policy shock are comparable, we need to include an exhaustive list of control variables that may be relevant for new bond yield rates. Now we describe our control variables, which include bond level controls, bond issuer controls, bond market level controls, and macroeconomic factors.

Bond Level Controls. For bond level controls we include the following variables from WIND: quantity of issuance; term; guaranteed or not; issued by SOE or not; puttable bond or not; callable bond or not;

Bond Issuer Controls. For bond issuer controls we include the following variables from WIND: debt to asset ratio; liquidity ratio; cash coverage ratio; logarithm of asset; logarithm of equity.

Bond Market Level Controls. For bond market level controls, we include the following variables from WIND: daily total new issuance of bonds of the same rating category (AAA, AA+, or AA) and same type (financial bond, corporate bond, enterprise bond, medium term note) in the same market (a variable that is referred to as "Similar Bond Issuance" in Table 9); daily issuance of Treasury bonds (Chinese Government Bonds, CGB); and daily issuance of local government bonds (China Municipal Bonds, CMB).

Macroeconomic Factors. It is also important for us to account for macroeconomics factors other than the MLF collateral expansion on June 1, 2018. We control for quarterly growth rate of GDP in the province of the issuer, which we obtain from China Statistical Yearbook. In addition, we control for the monthly M2 growth rate, which we obtain from the People's Bank of China. Finally, we control for the impact from the $100 \mathrm{bps}$ bank reserve requirements ratio (RRR) cut on April 25, 2018 for commercial and foreign banks to pay back loans obtained via MLF ${ }^{33}$ To allow for the possibility that the RRR cut impacts the spread of corporate bonds differently in the interbank market and the exchange market, we add a series of control

\footnotetext{
${ }^{33}$ The reserve requirement ratio (RRR) was 17 percent for large banks, and 15 percent for smaller banks. The move injected an estimated 1.3 Trillion yuan into the money market, 900 billion of which were used to repay loans via MLF, and 400 billion yuan were injected into banking system. See Economic Watch: China's monetary policy unchanged despite reserve requirement cut at: http://www.xinhuanet.com/english/2018-04/19/c_137121802.htm.
} 
variables to account for the RRR cut impact, including $R R R$ cut $t_{i} \times A A A_{i}, R_{R} R_{c u t} \times A A p l u s_{i}$, RRRcut $_{i} \times A A A_{i} \times I B_{i}, R_{R} R$ cut $_{i} \times A A$ plus $_{i} \times I B_{i}$, where $R R R c u t_{i}$ is a dummy equals 1 if the date of issuance is after April 25, 2018 and 0 otherwise, $I B_{i}$ is a dummy which equals to 1 if the bond is listed in interbank market, AAA is a dummy if the bond is AAA rated corporate bond, and AAplus is a dummy if the bond is AA+ rated corporate bond.

\subsection{Baseline Regression Specifications}

Our baseline equation for the primary market is based on the following triple-differences (DDD) specification:

$$
\begin{aligned}
\text { Spread }_{i t} & =\beta_{1} \text { Post }_{t}+\beta_{2} \text { Treat }_{i}+\beta_{3} I B_{i}+\beta_{4} \text { Post }_{t} \times \text { Treat }_{i}+\beta_{5} \text { Post }_{t} \times I B_{i} \\
& +\beta_{6} \text { Treat }_{i} \times I B_{i}+\beta_{7} \text { Post }_{t} \times \text { Treat }_{i} \times I B_{i}+\gamma \mathbf{X}_{i t}+\theta_{t}+\varepsilon_{i t}
\end{aligned}
$$

where $\operatorname{Spread}_{i t}$, the dependent variable, is the yield of bond $i$ issued at date $t$ relative to the yield of CGB bonds at date $t$; Post P $_{t}$ is a dummy which equals to 1 if issue date $t$ was after June 1, 2018, and 0 otherwise; Treat $_{i}$ is a dummy which equals to 1 if bond $i$ belongs to the categories of bonds that became newly eligible for MLF collaterals on June 1, 2018, i.e. corporate bonds rated AA and AA+, and financial bonds of Xiaowei, Green and Sannong firms rated AA or higher; $I B_{i}$ is a dummy which equals to 1 if bond $i$ is issued in the interbank market; $\mathbf{X}_{i t}$ is a list of control variables discussed in the previous section; and finally, $\theta_{t}$ are quarter fixed effects. We focus specifically on coefficient $\beta_{7}$ for the triple interaction term Post $_{t} \times$ Treat $_{i} \times I B_{i}$.

Table 9 presents the summary statistics of the variables used for primary market analysis. Panel A shows that, of the 1,791 new bond issuances in our sample of 1/1/2018-12/31/2018, $1090(60.9 \%$ of the total) were issued in the interbank market and 701 (39.1\%) in the exchange market; $37.8 \%$ of the new bond issuance took place after June 1, 2018; and about $43.3 \%$ of the new bonds were treated bonds. The mean issuance size of the new bonds is 1.39 billion yuan, and the bonds issued in the interbank market tend to have a larger size than those issued in the exchange market: 1.50 Billion yuan for the interbank market vs. 1.2 billion yuan for the exchange market. The mean terms to maturity are about 4.28 years, and those issued in the interbank market have a slightly longer term. Panel B shows that $53 \%$ of the new bonds are rated AAA, $28 \%$ AA+, and $19 \%$ AA. Panel $\mathrm{C}$ shows that $89 \%$ of the new bonds are corporate bonds, and about $11 \%$ are financial bonds.

[Table 9 About Here]

\subsection{Baseline Result, Robustness Checks and Heterogeneous Analysis}

Baseline Result. Table 10 presents the baseline results. The coefficient of particular interest is that of the interaction term Post $_{t} \times$ Treat $_{i} \times I B_{i}$, which is estimated to be negative and statistically significantly in all specifications. In Columns (1)-(5), the regression is weighted by bond issuance sizes. In our view, the bond issuance size weighted regressions provides a more useful estimate on 
how the collateral expansion affects the overall funding cost of borrowers in the economy. In the preferred specification where we include all the relevant control variables, we find that the spread of the treated bonds is 53.8 bps lower in the treatment market (the interbank market) relative to the control market (the control market). The estimates suggests, for a firm issuing 1.4 billion yuan corporate bond (which is the mean bond issuance size of our sample) with semi-annual coupon payment, the expansion of MLF collateral will save its borrowing cost for over 7.53 million yuan every year. This is a substantial reduction in the funding cost of the firms that issue treated bonds in the interbank market. In Column (6), we also report the results from an unweighted regression, where we estimate that the MLF collateral expansion reduces the spread of treated bonds by 37.1 bps.

[Table Table 10 About Here]

Parallel Trends and Dynamic Effects. In order to examine the parallel trend assumption necessary for the DDD strategy specified in (8) to work, we also estimated the following specification:

$$
\begin{aligned}
\text { Spread }_{i t} & =\beta_{1} \text { Post }_{t}+\beta_{2} \text { Treat }_{i}+\beta_{3} I B_{i}+\beta_{4} \text { Post }_{t} \times \text { Treat }_{i}+\beta_{5} \text { Post }_{t} \times I B_{i} \\
& +\beta_{6} \text { Treat }_{i} \times I B_{i}+\sum_{k=1, k \neq 5}^{k=9} \alpha_{k} \text { Month }_{i t}^{k} \times \text { Treat }_{i} \times I B_{i}+\gamma \mathbf{X}_{i t}+\theta_{t}+\varepsilon_{i t}
\end{aligned}
$$

where Month $h_{i t}^{k}$ is dummy which equals 1 if bond $i$ is issued in the $k^{\text {th }}$ month in 2018. We normalize the dummy for the fifth $(k=5)$ month to 0 as the benchmark.

[Figure 9 about Here]

Figure 9 presents the estimated values of $\alpha_{k}$ based on equation $(9)$ for $k \in\{1, \ldots, 9\}$. It shows that, prior to the policy shock, the $\alpha_{k}$ estimates are small and tend to be statistically insignificant, i.e., before the policy shock, the difference in the spreads in the interbank market and in the exchange market are similar for the treated bonds and for the control bonds. After the policy shock, the spreads of treated bonds in the interbank market are significantly reduced relative to the control bonds. The effect is immediate and persisted for all three months after the policy shock in our estimation sample.

Seasonal Effect? A Placebo Test. We used only the new bond issuance data within three months of the policy shock to deal with the potential selection bias from "movers" choosing to issue their bonds in the interbank market. This short post-policy sample period, however, introduces a possible concern: maybe the changes in the difference of the spreads of the treated bonds in the interbank market and in the exchange market are driven by a seasonal effect that differentially impacts the interbank market and the exchange market, instead of the policy effect. To address such a concern, we conduct the following placebo test: we use the new bond issuance data for bonds 
issued between 1/1/2015 and 8/31/2015 to re-run regression equation (8), setting June 1, 2015 as the factitious policy date ${ }^{34}$ The variable Post $_{t}$ is redefined so that it equals 1 if the bond is issued after June 1, 2015, and 0 otherwise.

Table 11 reports the result from this placebo test. We find that, different from the findings reported in Table 10, the coefficient estimates of the triple interaction term Post $_{t} \times$ Treat $_{i} \times I B_{i}$ in this placebo test tend to be statistically insignificant, and if anything, of a positive sign. This implies that seasonal factors are unlikely the driver for the findings reported in Table 10.

[ Table 11 about Here]

Heterogeneous Analysis. It is also interesting to see whether there are heterogeneous effects of the expansion of the collateral eligible bonds for MLF depending on the sector of the bond issuer. Table 12 reports the regression results from heterogeneous analysis, where we add additional interaction terms of Post $_{t} \times$ Treat $_{i} \times I B_{i}$ with Green and Sannong. We find that the patterns are generally consistent with those in the secondary market. The Green and Sannong bonds see a larger decrease in spread 45 The magnitude of the impact is large for these bonds, ranging from 2-4 times the impact of an average targeted bonds.

\section{[ Table 12 about Here]}

Shopping for "Venue"? Results reported in Table 10 provide strong evidence that the collateral expansion monetary policy reduced the yield of the targeted bonds in the interbank market relative to that in the exchange market. This of course has direct implications of funding costs for the firms issuing the targeted bonds in the interbank market. An additional implication is that, to the extent that bond issuers have a choice of which market - the interbank market or the exchange market - to issue their bonds, we may expect that eligible firms would take advantage of the policy and issue bonds in interbank market. We call this phenomenon "shopping for venue." Recall that any new bond issuance application needs to be submitted to NDRC for approval, which takes about two to three months typically. That is, even though the policy shock occurred on June 1, 2018, the effect of the policy on the venue of the new bond issuance should not manifest itself until at

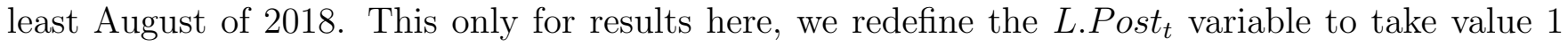
if $t$ is after August 1, 2018. In addition, we include all new bonds issued before 12/31/2018 in our analysis sample 36

To test this hypothesis, we estimate the following logistic regression model:

$$
I B_{i t}=\alpha_{1} \text { Post }_{t}+\alpha_{2} \text { Treat }_{i}+\alpha_{3} \text { Post }_{t} \times \text { Treat }_{i}+\gamma \mathbf{X}_{i t}+\varepsilon_{i t},
$$

\footnotetext{
${ }^{34}$ We choose the data from 2015 for the placebo test because China Securities Depository \& Clearing Co. Ltd (CSDC) introduced important changes to the bond market both in 2017 and 2016.

${ }^{35}$ We did not examine the heterogeneity between Xiaowei Bonds and other bonds because there were only two new Xiaowei Bond issued during 1/1/2018-08/31/2018.

${ }^{36}$ Table A.1 in the on-line appendix provides the summary statistics of the sample of all bonds issued in 2018 used in the analysis reported in Table 13 .
} 
where the dependent variable $I B_{i t}=1$ if new bond $i$ is issued in the interbank market at date $t$; Post $_{t}=1$ if the bond issuance date $t$ is after August 1, 2018; Treat ${ }_{i}=1$ if bond $i$ is one of the targeted bonds; $\mathbf{X}_{i t}$ stands for the same sets of control variables we described in Subsection 5.1 . and the coefficient of interest is $\alpha_{3}$ for the interaction term Post $_{t} \times$ Treat $_{i}$. We expect that $\alpha_{3}$ will be positive and statistically significant if targeted firms engage in venue shopping in that they are more likely to apply to NDRC to issue their bonds in the interbank market after the policy shock.

$$
\text { [ Table } 13 \text { about Here] }
$$

Table 13 presents the result from the logistic regressions specified by equation (10). In the preferred specification reported in Column (4) where we control for month fixed effects, as well as all the controls we described in Subsection 5.1, we find that, indeed, ceteris paribus, firms are more likely to apply to issue the treated bonds in the interbank market after the June 1, 2018 policy shock of MLF collateral expansion. The coefficient estimates of L.Post $\times$ Treat are positive and statistically significant. The coefficient estimates implies that, after June 1, 2018, the odds ratio that firms issuing treated bonds apply to have their bonds issued in the interbank market went up by 60 percent more relative to firms issuing control bonds. That is, firms are indeed more likely to choose the venue with a lower funding cost to issue their bonds.

\section{Conclusion}

In this paper, we provide a causal evaluation of collateral-based unconventional monetary policy on asset prices in the secondary market and on the real economy. This is an empirically challenging problem because of the well-known policy endogeneity problem. We in the estimation of the causal effects of collateral-based monetary policy, we exploit the unique institutional features of Chinese bond market, namely, dual-listed bonds are traded in two largely segmented markets: the interbank market regulated by the Central Bank, and the exchange market regulated by the securities regulator. During a policy shift in our study period (June 1, 2018), China's Central Bank included a class of previously ineligible bonds in the interbank market to become eligible collateral for financial institutions to borrow money from its Medium-Term Lending Facility (MLF). These bonds that were newly eligible as MLF collateral are referred to as "treated bonds". However, these treatment bonds are treated only in the interbank market ( "treatment market") but not in the exchange market (the "control market"). Since many of these treatment bonds are dual-listed in both markets, we can use the changes in the spread difference between the "control" and "treatment" bonds in the exchange market, which reflects the possibly differential impact of time varying factors on the two groups of bonds. as the counterfactual outcome of the treatment bonds, if they did not receive the treatment. Thus, this policy shift allows us to implement a triple-difference strategy to estimate the causal impact of the collateral-based unconventional monetary policy.

Our results provide corroborative support for the leverage cycle theory which predicts that the collateral eligibility of an asset for MLF will increase its price (i.e. reduce its spread) in the 
secondary market. We find the spreads of treated bonds in the secondary market are reduced by 42-62 bps on average. We also find that the collateral effects pass through to the primary bond market, where issuance spread of targeted bonds is reduced by 54 bps.

The finding is in support of effectiveness of collateral-based policy tool in reducing financial costs in the economy. The US Federal Reserve and the European Central Bank, as well as many other central banks, have been using collateral-based monetary policy extensively after the Great Financial Crisis. To the extent that in the modern collateral-based financial system, every financial contract is a pair of a promise and associated collateral to back the promise, the findings in this paper may suggest a stronger case for collateral-based monetary policy. Alongside the traditional interest-rate based tools, collateral-based tools can make monetary policy more effective in reducing financing cost in targeted sectors, both for economic and social purposes. In this case, the central bank can manage a collateral basket, and by changing the eligibility and haircuts of the collateral in the basket (intensive margin) and changing the composition of the collateral in the basket (extensive margin), the central banks can better navigate and moderate financial cycles and business cycles.

Many interesting questions remain to be answered. This paper provides evidence on price (spread) effect of monetary policy. To fully access the effects on corporate financing, evidence on quantity adjustment, e.g. issuance of bonds in the primary market, would also be informative. As important, we should also be cautious about the potential distortions caused by the collateral-based monetary policies. For instance, the policy may induce risk-taking of financial institutions towards certain bonds, worsen the quality of the overall collateral, and may also affect bond issuers' capital structure. These can increase the fragility of the financial system. The causal effects on these margins, and the design of the collateral-based monetary policy that strikes an optimal balance, are fascinating avenues for future research.

\section{References}

Acharya, Viral V, Tim Eisert, Christian Eufinger, and Christian Hirsch, "Whatever It Takes: The Real Effects Of Unconventional Monetary Policy," The Review of Financial Studies, 2019, 32 (9), 3366-3411.

Amihud, Yakov, "Illiquidity and Stock Returns: Cross-Section and Time-Series Effects," Journal of Financial Markets, 2002, 5 (1), 31-56.

Amstad, Marlene and Zhiguo He, "Chinese Bond Market and Interbank Market," Technical Report, National Bureau of Economic Research 2019.

Araújo, Aloísio, Susan Schommer, and Michael Woodford, "Conventional and unconventional monetary policy with endogenous collateral constraints," American Economic Journal: Macroeconomics, 2015, 7 (1), 1-43.

$\ldots, \ldots$, and _ , "Real Effects of Interest-rate Policy and Central-bank asset Purchases with Endogenous Collateral Constraints," 2019. 
Ashcraft, Adam, Nicolae Garleanu, and Lasse Heje Pedersen, "Two monetary tools: Interest rates and haircuts," NBER Macroeconomics Annual, 2011, 25 (1), 143-180.

Benetton, Matteo, Davide Fantino et al., Competition And The Pass-Through of Unconventional Monetary Policy: Evidence From TLTROs, Banca d'Italia, 2018.

Buiter, Willem. H., "Quantitative Easing And Qualitative Easing: A Terminological And Taxonomic Proposal," Financial Times, Willem Buiter's mavercon blog, 2008.

Chen, Hui, Zhuo Chen, Zhiguo He, Jinyu Liu, and Rengming Xie, "Pledgeability and Asset Prices: Evidence from the Chinese Corporate Bond Markets," University of Chicago, Becker Friedman Institute for Economics Working Paper, 2018, (2018-82).

Curdia, Vasco and Michael Woodford, "The Central-Bank Balance Sheet as an Instrument of Monetary Policy," Journal of Monetary Economics, 2011, 58 (1), 54-79.

Ding, Yi, Wei Xiong, and Jinfan Zhang, "Overpricing In China's Corporate Bond Market," Working Paper, The Chinese University of Hong Kong, Shenzhen and Princeton University, 2019.

Fiore, Fiorella De, Marie Hoerova, and Harald Uhlig, "Money Markets, Collateral And Monetary Policy," Technical Report, National Bureau of Economic Research 2018.

Fostel, Ana and John Geanakoplos, "Tranching, Cds, And Asset Prices: How Financial Innovation Can Cause Bubbles And Crashes," American Economic Journal: Macroeconomics, 2012, 4 (1), $190-225$.

Freyaldenhoven, Simon, Christian Hansen, and Jesse M Shapiro, "Pre-Event Trends In The Panel Event-Study Design," American Economic Review, 2019, 109 (9), 3307-38.

Galbraith, John Kenneth, The Great Crash 1929, Houghton Mifflin Harcourt, 2009.

Garleanu, Nicolae and Lasse Heje Pedersen, "Margin-Based Asset Pricing And Deviations From The Law Of One Price," The Review of Financial Studies, 2011, 24 (6), 1980-2022.

Geanakoplos, John, "Promises, promises," The Economy As An Evolving Complex System Ii, 1997, $27,285$.

_ , "The Leverage Cycle," Nber Macroeconomics Annual, 2010, 24 (1), 1-66.

_ and Haobin Wang, "Quantitative Easing, Collateral Constraints, and Financial Spillovers," 2018.

- and William R Zame, "Collateral Equilibrium, I: A Basic Framework," Economic Theory, 2014, $56(3), 443-492$.

Gertler, Mark and Peter Karadi, "A Model Of Unconventional Monetary Policy," Journal of monetary Economics, 2011, 58 (1), 17-34.

Gorton, Gary and Andrew Metrick, "Securitized Banking And The Run On Repo," Journal of Financial economics, 2012, 104 (3), 425-451.

Hansman, Christopher, Harrison Hong, Wenxi Jiang, Yu-Jane Liu, and Juan-Juan Meng, "Riding The Credit Boom," Technical Report, National Bureau of Economic Research 2018. 
Joyce, Michael, David Miles, Andrew Scott, and Dimitri Vayanos, "Quantitative Easing And Unconventional Monetary Policy-An Introduction," The Economic Journal, 2012, 122 (564), F271F288.

Krishnamurthy, Arvind, Stefan Nagel, and Annette Vissing-Jorgensen, "Ecb Policies Involving Government Bond Purchases: Impact And Channels," Review of Finance, 2017, 22 (1), 1-44.

Lenel, Moritz, "Safe Assets, Collateralized Lending and Monetary Policy," Technical Report, SIEPR Discussion Paper 2017.

Maggio, Marco Di, Amir Kermani, and Christopher Palmer, "How Quantitative Easing Works: Evidence On The Refinancing Channel," Technical Report, National Bureau of Economic Research 2016.

Nakamura, Emi and Jon Steinsson, "Identification in Macroeconomics," Journal of Economic Perspectives, 2018, 32 (3), 59-86.

Nyborg, Kjell G, "Central Bank Collateral Frameworks," Journal of Banking and Finance, 2017, $76,198-214$.

_, Collateral Frameworks: The Open Secret Of Central Banks, Cambridge University Press, 2017.

Piazzesi, Monika and Martin Schneider, "Payments, Credit And Asset Prices," 2017.

Rodnyansky, Alexander and Olivier M Darmouni, "The Effects Of Quantitative Easing On Bank Lending Behavior," The Review of Financial Studies, 2017, 30 (11), 3858-3887.

Schwert, Michael, "Municipal Bond Liquidity And Default Risk," The Journal of Finance, 2017, $72(4), 1683-1722$.

van Bekkum, Sjoerd, Marc Gabarro, and Rustom M Irani, "Does a Larger Menu Increase Appetite? Collateral Eligibility and Credit Supply," The Review of Financial Studies, 2017, 31 (3), 943-979.

Wang, Yongqin and Hongxun Xu, "How Leverage Affects Asset Prices: Evidence from a Natural Experiment in China's Bond Markets," Journal of Financial Research, 2019, (2), 1-19. 


\section{Tables and Figures}

Table 1: Collateral-based Monetary Policy Tools of People's Bank of China before 2018

\begin{tabular}{|c|c|c|c|c|}
\hline Name & $\begin{array}{l}\text { Short-term } \\
\text { Liquidity } \\
\text { Operation, } \\
\text { SLO }\end{array}$ & $\begin{array}{l}\text { Standing } \\
\text { Lending } \\
\text { Facility, } \\
\text { SLF }\end{array}$ & $\begin{array}{l}\text { Medium-term } \\
\text { Lending } \\
\text { Facility, } \\
\text { MLF }\end{array}$ & $\begin{array}{l}\text { Pledged } \\
\text { Supplementary } \\
\text { Lending, } \\
\text { PSL }\end{array}$ \\
\hline Launch time & 2013.1 & 2013.1 & 2014.9 & 2014.4 \\
\hline Maturity & $<7 \mathrm{D}$ & $1-3 \mathrm{M}$ & $3 \mathrm{M} / 6 \mathrm{M} / 1 \mathrm{Y}$ & $3-5 Y$ \\
\hline Collateral & $\begin{array}{l}\text { Treasury bonds, } \\
\text { central Bank bills, } \\
\text { policy bank financial bonds, } \\
\text { commercial bank bonds }\end{array}$ & $\begin{array}{l}\text { High credit rating } \\
\text { corporate bonds } \\
\text { and high quality asset }\end{array}$ & $\begin{array}{l}\text { Treasury bonds, } \\
\text { central Bank bills, } \\
\text { policy bank financial bonds, } \\
\text { corporate bonds and Sannong, } \\
\text { Green and Xiaowei bonds } \\
\text { rated at least AA }\end{array}$ & $\begin{array}{l}\text { High credit rating } \\
\text { corporate bonds and } \\
\text { high quality asset }\end{array}$ \\
\hline
\end{tabular}

Target

Small firms, agriculture

Projects with specific purpose

Note: The collaterals documented in this table are eligible assets for the corresponding monetary policy tools as of 2018. 
Table 2: Summary Statistics for Secondary Market: All Bonds

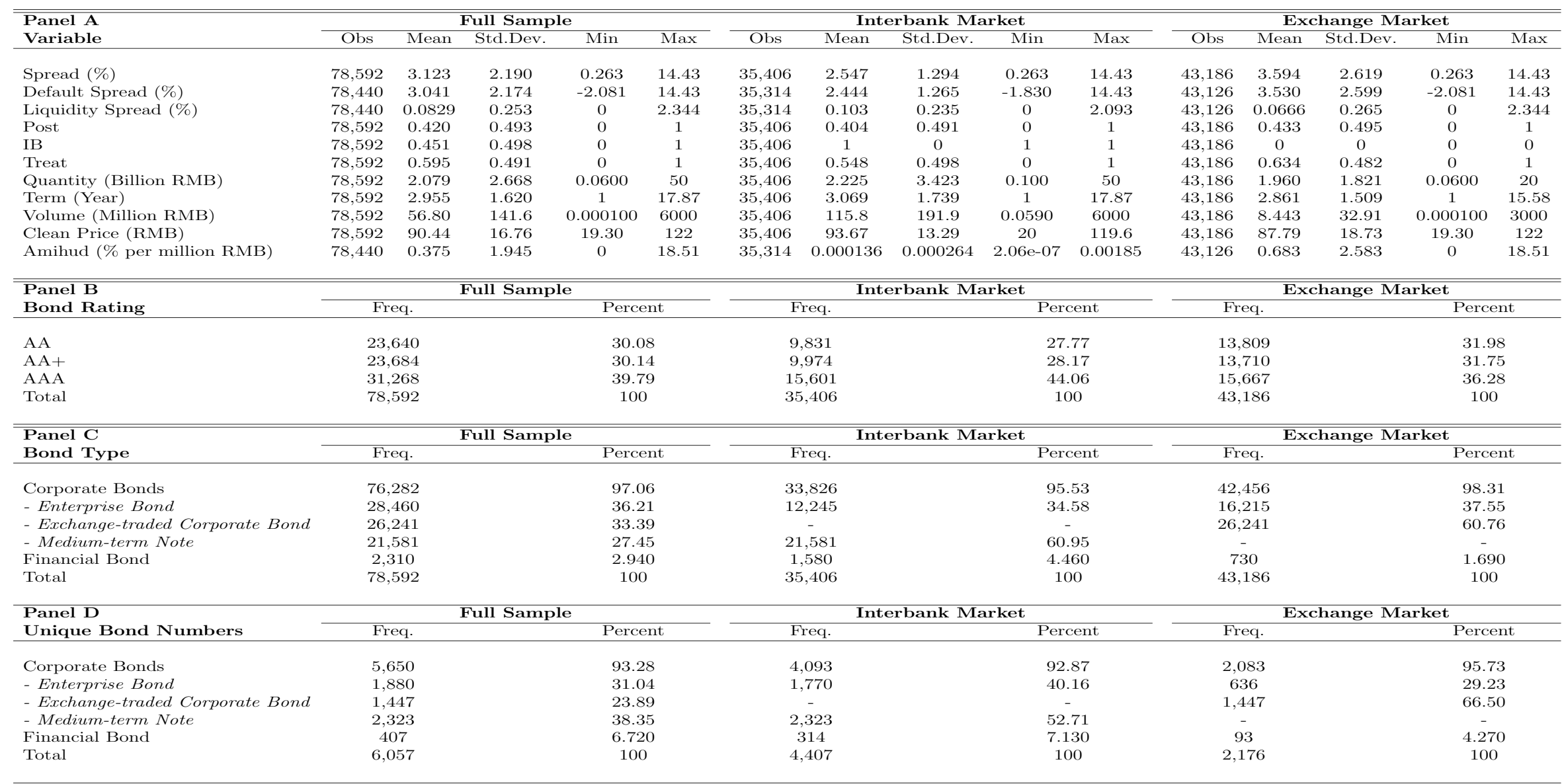

Note: This table provides sample summary statistics for variables used in our secondary market baseline regressions. Panel A describes the variables used in the regressions in Section 4. Spread, Default Spread, and Liquidity Spread are in percentage term. Post is a dummy which equals 1 if the date is after June 1, 2018; and 0 , otherwise. IB is a dummy which equals 1 if the bond is listed in interbank market, and 0 otherwise. Treat is a dummy which equals 1 if the bond is corporate bonds rated AA and AA+ and financial bond in the targeted sectors rated at least AA, and 0 otherwise. Quantity is the total value of the bond issuance, measured in billion-yuan term. Term is the bond's remaining terms to maturity, measured in year. Volume is the daily trading volume of the bond, measured in million-yuan term. Clean Price is the clean close price of bonds, measured in RMB. Amihud is estimated from regressions with Eq. 44, quarter by quarter, measured in percentages. 
Table 3: Summary Statistics for Secondary Markets: Dual-listed Bonds Only

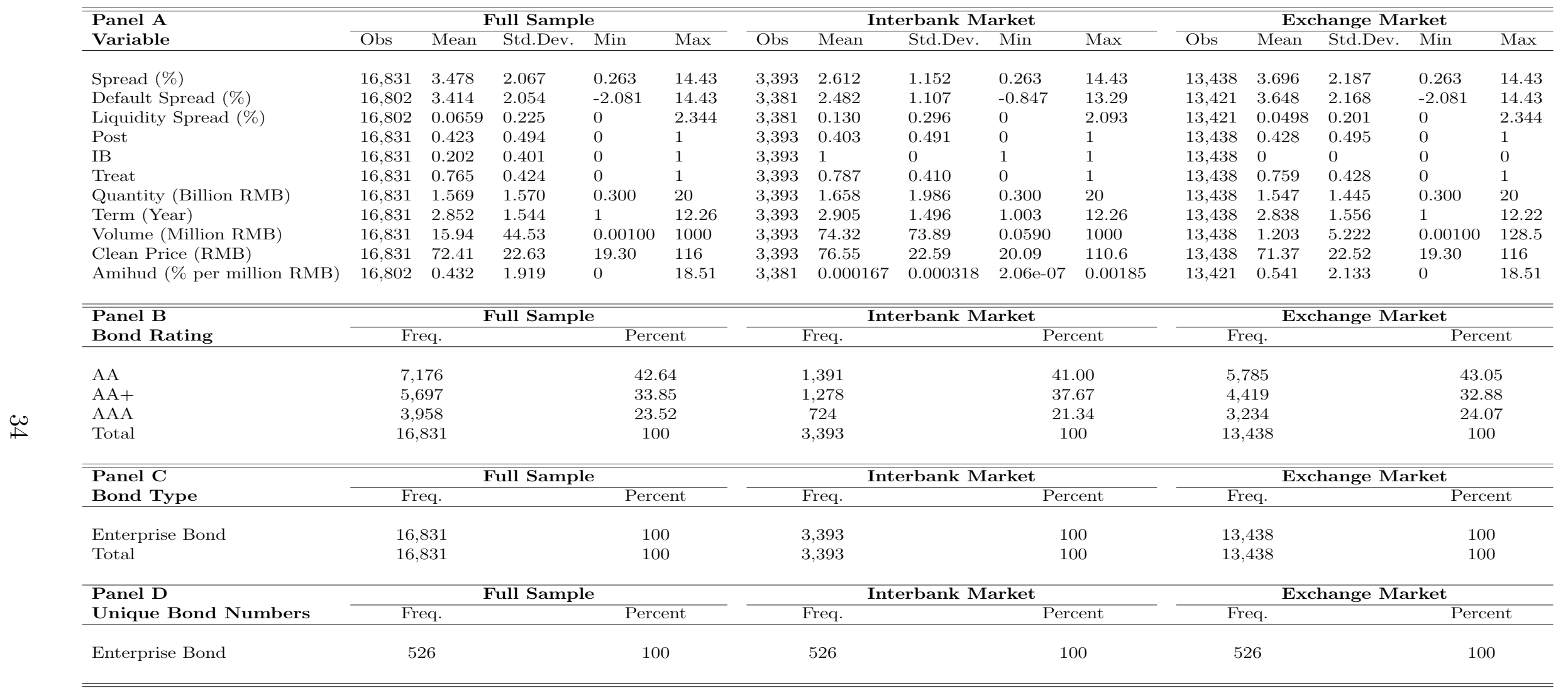

Note: This table provides sample summary statistics for variables used in our secondary market baseline regressions. Panel A describes the variables used in the regressions in Section 4. Spread, Default Spread, and Liquidity Spread are in percentage term. Post is a dummy which equals 1 if the date is after June 1, 2018; and 0, otherwise. IB is a dummy which equals 1 if the bond is listed in interbank market, and 0 otherwise. Treat is a dummy which equals 1 if the bond is corporate bonds rated AA and AA+ and financial bond in the targeted sectors rated at least AA, and 0 otherwise. Quantity is the total value of the bond issuance, measured in billion-yuan term. Term is the bond's remaining terms to maturity, measured in year. Volume is the daily trading volume of the bond, measured in million-yuan term. Clean Price is the clean close price of bonds, measured in RMB. Amihud is estimated from regressions with Eq. [4, quarter by quarter, measured in percentages. 
Table 4: Differences between the Spreads of Dual-listed Bonds in the Interbank and Exchange Markets

\begin{tabular}{|c|c|c|c|c|c|c|c|c|}
\hline \multicolumn{9}{|l|}{ Panel A } \\
\hline Absolute Difference in Spreads (bps) & $\begin{array}{l}\text { Obs } \\
1,179\end{array}$ & $\begin{array}{l}\text { Mean } \\
109.2\end{array}$ & $\begin{array}{l}\text { Std.Dev. } \\
135.4\end{array}$ & $\begin{array}{l}\text { Min } \\
0.0185\end{array}$ & $\begin{array}{l}\text { Max } \\
1166\end{array}$ & & & \\
\hline \multicolumn{9}{|l|}{ Panel B } \\
\hline Absolute Difference in Spreads (bps) & $0-0.1$ & $0.1-1$ & $1-5$ & $5-10$ & $10-50$ & $50-100$ & $100+$ & Total \\
\hline Obs. & 8 & 34 & 76 & 47 & 309 & 272 & 433 & 1,179 \\
\hline Percentage & $0.68 \%$ & $2.88 \%$ & $6.45 \%$ & $3.99 \%$ & $26.21 \%$ & $23.07 \%$ & $36.73 \%$ & $100.00 \%$ \\
\hline
\end{tabular}

Note: This table presents the absolute value of the difference between the spreads in the interbank market and the exchange market for the same bond, based on "simultaneous transactions," following the construction in Chen et al. (2018). Denote the date of trasaction in the interbank market as $t$. If there are transactions of the same bond in the exchange market that falls within $[t-2, t+2]$ trading window, then these transactions are called the "simultaneous" exchange transaction. The difference between the spreads is simply the spread of the simultaneous exchange transaction closest to date $t$ minus the interbank spread in date $t$ of the same bond. 
Table 5: Baseline Regression Results for Secondary Market

\begin{tabular}{lcc}
\hline \hline & Full Sample & $\begin{array}{c}\text { Dual-listed Bonds } \\
\text { Only } \\
\text { Variables }\end{array}$ \\
\hline Post $\times$ Treat $\times$ IB & $(1)$ & $-0.419^{*}$ \\
& $-0.618^{* * *}$ & $(0.235)$ \\
Post $\times$ Treat & $(0.171)$ & \\
& $0.487^{* * *}$ & \\
Bond Type $\times$ Bond Rating $\times$ Date FE & $(0.153)$ & Yes \\
Market $\times$ Date FE & Yes & Yes \\
Bond FE & Yes & Yes \\
\hline Obs. & Yes & 16,661 \\
Adjusted $R^{2}$ & 77,731 & 0.812 \\
\hline \hline
\end{tabular}

Note: Regression equation is specified by (1). Standard errors are clustered at the bond level. ${ }^{* * *}$, ${ }^{* *}$, and ${ }^{*}$ represent statistical significance at $1 \%, 5 \%$ and $10 \%$, respectively. 
Table 6: The Spillover Effect of the MLF Collateral Expansion on the Interbank Market

\begin{tabular}{|c|c|c|}
\hline Variables & $\begin{array}{l}\text { Full Sample } \\
\qquad(1)\end{array}$ & $\begin{array}{c}\text { Dual-listed Bonds } \\
\text { Only } \\
(2)\end{array}$ \\
\hline Post $\times$ Treat $\times$ IB & $\begin{array}{c}-0.614^{* * *} \\
(0.168)\end{array}$ & $\begin{array}{l}-0.447^{*} \\
(0.229)\end{array}$ \\
\hline Post $\times$ IB & $\begin{array}{l}-0.104 \\
(0.106)\end{array}$ & $\begin{array}{l}-0.343^{*} \\
(0.183)\end{array}$ \\
\hline Post $\times$ Treat & $\begin{array}{l}0.475^{* * *} \\
(0.147)\end{array}$ & \\
\hline $\begin{array}{l}\text { Bond Type } \times \text { Bond Rating } \times \text { Date FE } \\
\text { Bond FE }\end{array}$ & $\begin{array}{l}\text { Yes } \\
\text { Yes }\end{array}$ & $\begin{array}{l}\text { Yes } \\
\text { Yes }\end{array}$ \\
\hline $\begin{array}{l}\text { Obs. } \\
\text { Adjusted } R^{2}\end{array}$ & $\begin{array}{c}77,731 \\
0.859\end{array}$ & $\begin{array}{c}16,661 \\
0.811\end{array}$ \\
\hline
\end{tabular}

Note: Regression equation is specified by (3). Standard errors are clustered at the bond level. ${ }^{* * *},{ }^{* *}$, and ${ }^{*}$ represent statistical significance at $1 \%, 5 \%$ and $10 \%$, respectively. 
Table 7: Liquidity Spread vs. Default Spread in the Secondary Market

\begin{tabular}{|c|c|c|c|c|c|c|}
\hline \multirow[b]{2}{*}{ Variables } & \multicolumn{3}{|c|}{ Full Sample } & \multicolumn{3}{|c|}{ Dual-listed Bonds Only } \\
\hline & $\begin{array}{c}\text { Total Spread } \\
\text { (1) }\end{array}$ & $\begin{array}{l}\text { Liquidity Spread } \\
(2)\end{array}$ & $\begin{array}{c}\text { Default Spread } \\
(3)\end{array}$ & $\begin{array}{c}\text { Total Spread } \\
(4)\end{array}$ & $\begin{array}{l}\text { Liquidity Spread } \\
(5)\end{array}$ & $\begin{array}{c}\text { Default Spread } \\
(6)\end{array}$ \\
\hline Post $\times$ Treat $\times$ IB & $\begin{array}{c}-0.618^{* * *} \\
(0.171)\end{array}$ & $\begin{array}{c}0.0662^{* * *} \\
(0.0235)\end{array}$ & $\begin{array}{c}-0.682^{* * *} \\
(0.168)\end{array}$ & $\begin{array}{l}-0.419^{*} \\
(0.235)\end{array}$ & $\begin{array}{r}-0.00123 \\
(0.0393)\end{array}$ & $\begin{array}{l}-0.416^{*} \\
(0.228)\end{array}$ \\
\hline Post $\times$ Treat & $\begin{array}{c}0.487^{* * *} \\
(0.153)\end{array}$ & $\begin{array}{c}-0.0966^{* *} \\
(0.0445)\end{array}$ & $\begin{array}{c}0.581^{* * *} \\
(0.159)\end{array}$ & & & \\
\hline Bond Type $\times$ Bond Rating $\times$ Date FE & Yes & Yes & Yes & Yes & Yes & Yes \\
\hline Market $\times$ Date FE & Yes & Yes & Yes & Yes & Yes & Yes \\
\hline Bond FE & Yes & Yes & Yes & Yes & Yes & Yes \\
\hline Obs. & 77,731 & 77,579 & 77,579 & 16,661 & 16,631 & 16,631 \\
\hline Adjusted $R^{2}$ & 0.860 & 0.275 & 0.854 & 0.812 & 0.337 & 0.811 \\
\hline
\end{tabular}

Note: Regression equation is specified by (1) for Columns (1) and (4); for Columns (2) and (5), the dependent variables are replaced by the liquidity spread constructed in (6); and for Columns (3) and(6), they ar replaced by the default spread constructed in (7). Standard errors are clustered at the bond level. ${ }^{* * *},{ }^{* *}$, and ${ }^{*}$ represent statistical significance at $1 \%, 5 \%$ and $10 \%$, respectively. 
Table 8: Heterogeneous Effects on Spreads in the Secondary Market

\begin{tabular}{lcccc}
\hline \hline Variables & $(1)$ & $(2)$ & $(3)$ & $(4)$ \\
\hline Post $\times$ Treat & & & & \\
& 0.00373 & $0.470^{* * *}$ & $0.485^{* * *}$ & -0.110 \\
Post $\times$ Treat $\times$ IB & $(0.406)$ & $(0.153)$ & $(0.153)$ & $(0.469)$ \\
& $-0.620^{* * *}$ & $-0.602^{* * *}$ & $-0.618^{* * *}$ & $-0.604^{* * *}$ \\
Post $\times$ Treat $\times$ IB $\times$ Green & $(0.171)$ & $(0.171)$ & $(0.171)$ & $(0.171)$ \\
& 0.511 & & & 0.581 \\
Post $\times$ Treat $\times$ IB $\times$ Xiaowei & $(0.401)$ & & & $(0.450)$ \\
& & $-0.476^{* * *}$ & & $-0.473^{* * *}$ \\
Post $\times$ Treat $\times$ IB $\times$ Sannong & & $(0.0736)$ & & $(0.0737)$ \\
Bond Type $\times$ Bond Rating $\times$ Date FE & Yes & & 0.0392 & 0.620 \\
Market $\times$ Date FE & Yes & Yes & Yes & Yes \\
Bond FE & Yes & Yes & Yes & Yes \\
\hline Obs. & 77,731 & 77,731 & 77,731 & 77,731 \\
Adjusted $R^{2}$ & 0.860 & 0.860 & 0.860 & 0.860 \\
\hline \hline
\end{tabular}

Note: Regression equation is similar to that specified by 1 , with the addition of the quadruple interaction terms of Post $\times$ Treat $\times$ IB with Green, Xiaowei and Sannong respectively to capture the heterogeneous effects. Full sample is used in the regressions. Standard errors are clustered at the bond level. ${ }^{* * *},{ }^{* *}$, and ${ }^{*}$ represent statistical significance at $1 \%, 5 \%$ and $10 \%$, respectively. 
Table 9: Summary Statistics for the Primary Market Data: 2018/1/1-2018/8/31

\begin{tabular}{|c|c|c|c|c|c|c|c|c|c|c|c|c|c|c|c|c|}
\hline \multirow{2}{*}{$\begin{array}{l}\text { Panel A } \\
\text { Variables }\end{array}$} & & \multicolumn{5}{|c|}{$\begin{array}{l}\text { Full Sample } \\
\end{array}$} & \multirow{2}{*}{\multicolumn{5}{|c|}{$\begin{array}{r}\text { Interbank Market } \\
\text { Mean Std.Dev Min }\end{array}$}} & \multicolumn{5}{|c|}{ Exchange Market } \\
\hline & & Obs & Mean & Std.Dev. & Min & Max & & & & Min & & Obs & Mean & Std.Dev. & Min & Max \\
\hline Dep.Var. & Spread & 1,791 & 2.537 & 1.029 & 0.503 & 5.889 & 1,090 & 2.500 & 0.988 & 0.568 & 5.249 & 701 & 2.594 & 1.087 & 0.503 & 5.889 \\
\hline \multirow[t]{3}{*}{ Dummies } & Post & 1,791 & 0.378 & 0.485 & 0 & 1 & 1,090 & 0.347 & 0.476 & 0 & 1 & 701 & 0.427 & 0.495 & 0 & 1 \\
\hline & IB & 1,791 & 0.609 & 0.488 & 0 & 1 & 1,090 & 1 & 0 & 1 & 1 & 701 & 0 & 0 & 0 & 0 \\
\hline & Treat & 1,791 & 0.433 & 0.496 & 0 & 1 & 1,090 & 0.484 & 0.500 & 0 & 1 & 701 & 0.354 & 0.478 & 0 & 1 \\
\hline \multirow[t]{5}{*}{ Bond Info } & Quantity (Billion RMB) & 1,791 & 1.389 & 1.930 & 0.0300 & 40 & 1,090 & 1.504 & 2.322 & 0.0800 & 40 & 701 & 1.211 & 1.042 & 0.0300 & 7.200 \\
\hline & Term & 1,791 & 4.275 & 1.846 & 0.917 & 15 & 1,090 & 4.393 & 2.016 & 2 & 15 & 701 & 4.093 & 1.527 & 0.917 & 15 \\
\hline & $\begin{array}{l}\text { Guarantee } \\
\text { SOE }\end{array}$ & 1,791 & $\begin{array}{l}0.111 \\
0.782\end{array}$ & $\begin{array}{l}0.314 \\
0.413\end{array}$ & $\begin{array}{l}0 \\
0 \\
0\end{array}$ & & $\begin{array}{l}1,090 \\
1,090\end{array}$ & $\begin{array}{l}0.105 \\
0.858\end{array}$ & $\begin{array}{l}0.306 \\
0.349\end{array}$ & 0 & 1 & 701 & 0.121 & 0.327 & 0 & 1 \\
\hline & Put & $\begin{array}{l}1,791 \\
1,791\end{array}$ & $\begin{array}{l}0.782 \\
0.341\end{array}$ & $\begin{array}{l}0.413 \\
0.474\end{array}$ & $\begin{array}{l}0 \\
0\end{array}$ & 1 & $\begin{array}{l}1,090 \\
1,090\end{array}$ & $\begin{array}{l}0.858 \\
0.158\end{array}$ & $\begin{array}{l}0.349 \\
0.365\end{array}$ & $\begin{array}{l}0 \\
0\end{array}$ & $\begin{array}{l}1 \\
1\end{array}$ & 701 & $\begin{array}{l}0.665 \\
0.626\end{array}$ & 0.472 & 0 & 1 \\
\hline & Call & 1,791 & 0.0882 & 0.284 & 0 & 1 & 1,090 & $\begin{array}{l}0.138 \\
0.120\end{array}$ & $\begin{array}{l}0.363 \\
0.325\end{array}$ & 0 & 1 & 701 & 0.0385 & 0.193 & 0 & 1 \\
\hline \multirow{5}{*}{ Issuer Info } & Detb Asset Ratio & 1,791 & 62.33 & 18.23 & 0 & 95.59 & 1.090 & 62.17 & 18.70 & 0 & 95.17 & 701 & 62.58 & 17.48 & 0 & 95.59 \\
\hline & Liquidity Ratio & 1,791 & 3.795 & 68.24 & 0 & 2887 & 1,090 & 5.194 & 87.45 & 0 & 2887 & 701 & 1.619 & 1.774 & 0 & 26.46 \\
\hline & Cash Coverage Ratio & 1,791 & 0.501 & 2.048 & -2.571 & 3.024 & 1,090 & 0.431 & 2.070 & -2.571 & 3.024 & 701 & 0.610 & 2.010 & -2.571 & 3.024 \\
\hline & Log Assets & 1,766 & 24.99 & 1.394 & 19.93 & 30.68 & 1,078 & 25.04 & 1.424 & 20.76 & 30.68 & 688 & 24.91 & 1.342 & 19.93 & 27.78 \\
\hline & Log Equity & 1,766 & 23.86 & 1.259 & 19.35 & 29.00 & 1,078 & 23.90 & 1.281 & 19.84 & 29.00 & 688 & 23.80 & 1.221 & 19.35 & 26.64 \\
\hline \multirow[t]{3}{*}{ Market Info } & Similar Bond Issuance (Billion RMB) & 1,791 & 4.885 & 5.037 & 0.0300 & 40 & 1,090 & 5.363 & 5.638 & 0.0800 & 40 & 701 & 4.144 & 3.812 & 0.0300 & 14.60 \\
\hline & CMB Issuance (Billion RMB) & 1,791 & 24.82 & 34.79 & o & 176.9 & 1,090 & 18.38 & 22.72 & o & 88.44 & 701 & 34.84 & 46.11 & o & 176.9 \\
\hline & CGB Issuance (Billion RMB) & 1,791 & 16.80 & 61.68 & 0 & 500.2 & 1,090 & 15.51 & 50.78 & 0 & 250.1 & 701 & 18.81 & 75.56 & 0 & 500.2 \\
\hline \multirow[t]{9}{*}{ Macro Info } & $\triangle \mathrm{GDP}$ & 1,774 & 11.63 & 2.895 & -13.58 & 20.30 & 1,081 & 11.65 & 2.725 & -13.58 & 20.30 & 693 & 11.59 & 3.143 & -13.58 & 20.30 \\
\hline & $\Delta \mathrm{M} 2$ & 1,791 & 8.869 & 0.276 & 8.174 & 9.233 & 1,090 & 8.880 & 0.282 & 8.174 & 9.233 & 701 & 8.852 & 0.265 & 8.174 & 9.233 \\
\hline & $\mathrm{IB} \times \mathrm{AA}+$ & 1,791 & 0.180 & 0.385 & 0 & 1 & 1,090 & 0.296 & 0.457 & 0 & 1 & 701 & 0 & 0 & 0 & 0 \\
\hline & $\mathrm{IB} \times \mathrm{AAA}$ & 1,791 & 0.263 & 0.440 & 0 & 1 & 1,090 & 0.432 & 0.496 & 0 & 1 & 701 & 0 & 0 & 0 & 0 \\
\hline & RRRcut $\times$ IB & 1,791 & 0.321 & 0.467 & 0 & 1 & 1,090 & 0.528 & 0.499 & 0 & 1 & 701 & 0 & 0 & 0 & 0 \\
\hline & RRRcut $\times$ AA+ & 1,791 & 0.128 & 0.334 & 0 & 1 & 1,090 & 0.142 & 0.349 & 0 & 1 & 701 & 0.106 & 0.307 & 0 & 1 \\
\hline & RRRcut $\times$ AAA & 1,791 & 0.294 & 0.456 & 0 & 1 & 1,090 & 0.239 & 0.426 & 0 & 1 & 701 & 0.379 & 0.486 & 0 & 1 \\
\hline & RRRcut $\times$ IB $\times$ AA + & 1,791 & 0.0865 & 0.281 & 0 & 1 & 1,090 & 0.142 & 0.349 & 0 & 1 & 701 & o & 0 & 0 & 0 \\
\hline & RRRcut $\times$ IB $\times$ AAA & 1,791 & 0.145 & 0.352 & 0 & 1 & 1,090 & 0.239 & 0.426 & 0 & 1 & 701 & 0 & 0 & 0 & 0 \\
\hline \multirow{2}{*}{\multicolumn{2}{|c|}{$\begin{array}{l}\text { Panel B } \\
\text { Bond Rating }\end{array}$}} & \multirow{2}{*}{\multicolumn{5}{|c|}{ Full Sample }} & \multicolumn{5}{|c|}{ Interbank Market } & \multirow{2}{*}{\multicolumn{5}{|c|}{\begin{tabular}{ll}
\multicolumn{3}{c}{ Exchange Market } \\
Obs.
\end{tabular}}} \\
\hline & & & & & & & $\mathrm{Ol}$ & s. & & Per & ent & & & & & \\
\hline \multirow{4}{*}{ Rating } & AA & \multirow{2}{*}{\multicolumn{2}{|c|}{339}} & \multirow{2}{*}{\multicolumn{3}{|c|}{$\begin{array}{l}18.93 \\
27.75\end{array}$}} & 20 & 98 & & 19 & & & 131 & & 18 & \\
\hline & $\mathrm{AA}+$ & & & & & & 34 & 45 & & 31 & & & 152 & & & \\
\hline & AAA & & 55 & & & & 53 & 37 & & 49 & & & 418 & & & \\
\hline & Total & & 791 & & & & 1,0 & 90 & & 16 & & & 701 & & 10 & \\
\hline Panel C & & & & Full Sam! & & & & & erbank $\mathrm{N}$ & arket & & & & change $M$ & arket & \\
\hline Bond Type & & & bs. & & Per & & $\mathrm{Ol}$ & os. & & Per & ent & & bs. & & Per & ent \\
\hline & Corporate Bonds & & 596 & & & & $98>>2>>$ & 84 & & & & & 512 & & & \\
\hline & - Enterprise Bonds & & 41 & & & & 13 & 39 & & 12 & & & 2 & & 0.2 & \\
\hline Туре & - Exchange-traded Corporate Bonds & & 10 & & & & & & & & & & 510 & & 87. & \\
\hline & - Medium-term Notes & & 45 & & & & 84 & 45 & & 77 & & & - & & & \\
\hline & Financial Bonds & & & & & & & & & 9.7 & & & 89 & & 12 & \\
\hline & Total & & 791 & & & & 1,0 & 90 & & 10 & & & 701 & & 10 & \\
\hline Panel D & (Billion RMB) & Oux & ntity & Sull Sam & le & That & & Int & erbank $\mathrm{N}$ & arket & & & $\mathbf{E x}$ & hange $\mathrm{M}$ & arket & Thet 2 \\
\hline Issuance size & & Q 2112 & ntity & & Quanti & Tlotal & Quar & ntity & & Quantit & y/lotal & Qu & antity & & Quantit & y/Total \\
\hline & Corporate Bonc & & 15.8 & & & & 116 & 4.9 & & 71 & & & 50.9 & & 76 & \\
\hline & - Enterprise Bo & & 5.1 & & & & 12 & & & 7.4. & & & 200 & & 0.2 & \\
\hline Issuance & - Exchange-traded & & 8.7 & & & & & & & & & & 48.7 & & 76 & \\
\hline & - Medium-term Note & & 42 & & & & 10 & 42 & & 63 & & & & & 23 & \\
\hline & Financial Bonds & & 2.7 & & & & 47. & 4.5 & & 28 & & & 98.2 & & 23 & \\
\hline & Total & & 38.5 & & & & 163 & 39.4 & & 100 & & & 49.1 & & & \\
\hline
\end{tabular}

Note: See text in Section 5 for details of the variables. 
Table 10: Baseline Regression with Primary Market Data

\begin{tabular}{|c|c|c|c|c|c|c|}
\hline \multirow[b]{2}{*}{ Variables } & \multicolumn{5}{|c|}{ Weighted by Bond Issuance Size } & \multirow{2}{*}{$\begin{array}{c}\text { Unweighted } \\
\qquad(6)\end{array}$} \\
\hline & $(1)$ & $(2)$ & $(3)$ & $(4)$ & $(5)$ & \\
\hline Post & $\begin{array}{c}0.0442 \\
(0.0913)\end{array}$ & $\begin{array}{c}0.000862 \\
(0.0807)\end{array}$ & $\begin{array}{c}0.0502 \\
(0.0791)\end{array}$ & $\begin{array}{c}0.0996 \\
(0.0827)\end{array}$ & $\begin{array}{c}0.111 \\
(0.0867)\end{array}$ & $\begin{array}{l}-0.0465 \\
(0.0854)\end{array}$ \\
\hline Treat & $\begin{array}{c}0.966^{* * *} \\
(0.129)\end{array}$ & $\begin{array}{c}0.916^{* * *} \\
(0.128)\end{array}$ & $\begin{array}{c}0.824^{* * *} \\
(0.117)\end{array}$ & $\begin{array}{c}0.833^{* * *} \\
(0.117)\end{array}$ & $\begin{array}{c}0.594^{* * *} \\
(0.131)\end{array}$ & $\begin{array}{c}0.614^{* * *} \\
(0.111)\end{array}$ \\
\hline IB & $\begin{array}{c}-0.267^{* * * *} \\
(0.0805)\end{array}$ & $\begin{array}{l}-0.0957 \\
(0.0590)\end{array}$ & $\begin{array}{c}0.0314 \\
(0.0561)\end{array}$ & $\begin{array}{c}0.0214 \\
(0.0555)\end{array}$ & $\begin{array}{c}-0.623^{* * *} \\
(0.151)\end{array}$ & $\begin{array}{c}-0.866^{* * *} \\
(0.128)\end{array}$ \\
\hline IB $\times$ Treat & $\begin{array}{r}-0.0531 \\
(0.111)\end{array}$ & $\begin{array}{l}-0.187^{*} \\
(0.0954)\end{array}$ & $\begin{array}{c}-0.296^{* * *} \\
(0.0958)\end{array}$ & $\begin{array}{c}-0.298^{* * *} \\
(0.0963)\end{array}$ & $\begin{array}{c}0.0166 \\
(0.164)\end{array}$ & $\begin{array}{c}0.543^{* * *} \\
(0.146)\end{array}$ \\
\hline Post $\times$ Treat & $\begin{array}{c}0.870^{* * *} \\
(0.144)\end{array}$ & $\begin{array}{c}0.910^{* * *} \\
(0.160)\end{array}$ & $\begin{array}{c}0.885^{* * *} \\
(0.160)\end{array}$ & $\begin{array}{c}0.888^{* * *} \\
(0.162)\end{array}$ & $\begin{array}{c}0.838^{* * *} \\
(0.156)\end{array}$ & $\begin{array}{c}0.649^{* * *} \\
(0.120)\end{array}$ \\
\hline Post $\times$ IB & $\begin{array}{r}-0.0786 \\
(0.116)\end{array}$ & $\begin{array}{c}-0.109 \\
(0.0871)\end{array}$ & $\begin{array}{l}-0.137^{*} \\
(0.0824)\end{array}$ & $\begin{array}{l}-0.159^{*} \\
(0.0826)\end{array}$ & $\begin{array}{c}-0.206^{* *} \\
(0.0944)\end{array}$ & $\begin{array}{c}-0.154 \\
(0.103)\end{array}$ \\
\hline Post $\times$ Treat $\times$ IB & $\begin{array}{c}-0.547^{* * *} \\
(0.205)\end{array}$ & $\begin{array}{c}-0.525^{* * *} \\
(0.200)\end{array}$ & $\begin{array}{c}-0.479^{* *} \\
(0.194)\end{array}$ & $\begin{array}{c}-0.482^{* *} \\
(0.196)\end{array}$ & $\begin{array}{c}-0.538^{* * *} \\
(0.206)\end{array}$ & $\begin{array}{c}-0.371^{* *} \\
(0.169)\end{array}$ \\
\hline Quarter FE & Yes & Yes & Yes & Yes & Yes & Yes \\
\hline Bond Info. & No & Yes & Yes & Yes & Yes & Yes \\
\hline Bond Issuer Info. & No & No & Yes & Yes & Yes & Yes \\
\hline Market Info. & No & No & No & Yes & Yes & Yes \\
\hline Macro Factors & No & No & No & No & Yes & Yes \\
\hline Obs. & 1,791 & 1,791 & 1,766 & 1,766 & 1,757 & 1,757 \\
\hline Adjusted $R^{2}$ & 0.451 & 0.591 & 0.613 & 0.613 & 0.634 & 0.609 \\
\hline
\end{tabular}

Note: Regression equation is specified by 8. In Columns (1)-(5), the regression is weighted by bond issuance sizes. Column (6) reports the results from an unweighted regression. Standard errors are clustered at the bond level. ${ }^{* * *},{ }^{* *}$, and ${ }^{*}$ represent statistical significance at $1 \%, 5 \%$ and $10 \%$, respectively. 
Table 11: Placebo Test: Primary Market Data: Using June 1, 2015 as the Fictitious Event Date

\begin{tabular}{|c|c|c|c|c|c|c|}
\hline \multirow[b]{2}{*}{ Variables } & \multicolumn{5}{|c|}{ Weighted by Bond Issuance Size } & \multirow{2}{*}{$\begin{array}{c}\text { Unweighted } \\
(6)\end{array}$} \\
\hline & $(1)$ & $(2)$ & $(3)$ & $(4)$ & $(5)$ & \\
\hline Post & $\begin{array}{c}0.108 \\
(0.316)\end{array}$ & $\begin{array}{c}0.630 \\
(0.404)\end{array}$ & $\begin{array}{c}0.673 \\
(0.409)\end{array}$ & $\begin{array}{c}0.714^{*} \\
(0.399)\end{array}$ & $\begin{array}{c}0.701^{* *} \\
(0.337)\end{array}$ & $\begin{array}{c}0.662^{*} \\
(0.349)\end{array}$ \\
\hline Treat & $\begin{array}{l}0.574^{*} \\
(0.333)\end{array}$ & $\begin{array}{l}0.755^{*} \\
(0.394)\end{array}$ & $\begin{array}{l}0.678^{*} \\
(0.408)\end{array}$ & $\begin{array}{l}0.675^{*} \\
(0.400)\end{array}$ & $\begin{array}{l}0.689^{*} \\
(0.388)\end{array}$ & $\begin{array}{c}0.995^{* * *} \\
(0.316)\end{array}$ \\
\hline IB & $\begin{array}{c}-0.361^{*} \\
(0.201)\end{array}$ & $\begin{array}{c}0.140 \\
(0.346)\end{array}$ & $\begin{array}{c}0.195 \\
(0.353)\end{array}$ & $\begin{array}{c}0.115 \\
(0.345)\end{array}$ & $\begin{array}{l}-0.300 \\
(0.392)\end{array}$ & $\begin{array}{l}-0.273 \\
(0.356)\end{array}$ \\
\hline IB $\times$ Treat & $\begin{array}{l}0.586^{*} \\
(0.345)\end{array}$ & $\begin{array}{c}0.379 \\
(0.370)\end{array}$ & $\begin{array}{c}0.319 \\
(0.379)\end{array}$ & $\begin{array}{c}0.339 \\
(0.374)\end{array}$ & $\begin{array}{c}0.981^{* *} \\
(0.389)\end{array}$ & $\begin{array}{c}0.913^{* *} \\
(0.361)\end{array}$ \\
\hline Post $\times$ Treat & $\begin{array}{c}-0.514 \\
(0.451)\end{array}$ & $\begin{array}{c}-0.975^{* *} \\
(0.465)\end{array}$ & $\begin{array}{c}-1.002^{* *} \\
(0.471)\end{array}$ & $\begin{array}{c}-0.893^{* *} \\
(0.447)\end{array}$ & $\begin{array}{l}-0.650 \\
(0.466)\end{array}$ & $\begin{array}{c}-0.952^{* *} \\
(0.412)\end{array}$ \\
\hline Post $\times$ IB & $\begin{array}{r}-0.0968 \\
(0.331)\end{array}$ & $\begin{array}{l}-0.658 \\
(0.414)\end{array}$ & $\begin{array}{c}-0.726^{*} \\
(0.425)\end{array}$ & $\begin{array}{c}-0.680^{*} \\
(0.401)\end{array}$ & $\begin{array}{l}-0.545 \\
(0.340)\end{array}$ & $\begin{array}{l}-0.527 \\
(0.356)\end{array}$ \\
\hline Post $\times$ Treat $\times$ IB & $\begin{array}{c}0.138 \\
(0.473)\end{array}$ & $\begin{array}{c}0.687 \\
(0.484)\end{array}$ & $\begin{array}{c}0.742 \\
(0.495)\end{array}$ & $\begin{array}{c}0.678 \\
(0.472)\end{array}$ & $\begin{array}{c}0.515 \\
(0.483)\end{array}$ & $\begin{array}{c}0.791^{*} \\
(0.428)\end{array}$ \\
\hline Quarter FE & Yes & Yes & Yes & Yes & Yes & Yes \\
\hline Bond Info. & No & Yes & Yes & Yes & Yes & Yes \\
\hline Bond Issuer Info. & No & No & Yes & Yes & Yes & Yes \\
\hline Market Info. & No & No & No & Yes & Yes & Yes \\
\hline Macro Factors & No & No & No & No & Yes & Yes \\
\hline Obs. & 581 & 581 & 580 & 580 & 580 & 580 \\
\hline Adjusted $R^{2}$ & 0.367 & 0.556 & 0.554 & 0.567 & 0.617 & 0.552 \\
\hline
\end{tabular}

Note: Regression equation is specified by (8). In Columns (1)-(5), the regression is weighted by bond issuance sizes. Column (6) reports the results from an unweighted regression. Standard errors are clustered at the bond level. ${ }^{* * *},{ }^{* *}$, and ${ }^{*}$ represent statistical significance at $1 \%, 5 \%$ and $10 \%$, respectively. 
Table 12: Heterogeneous Analysis with Primary Market Data

\begin{tabular}{|c|c|c|c|}
\hline Variables & (1) & $(2)$ & $(3)$ \\
\hline Post & $\begin{array}{c}0.0997 \\
(0.0859)\end{array}$ & $\begin{array}{c}0.109 \\
(0.0867)\end{array}$ & $\begin{array}{c}0.0975 \\
(0.0858)\end{array}$ \\
\hline Treat & $\begin{array}{c}0.643^{* * *} \\
(0.134)\end{array}$ & $\begin{array}{c}0.589^{* * *} \\
(0.131)\end{array}$ & $\begin{array}{c}0.640^{* * *} \\
(0.135)\end{array}$ \\
\hline IB & $\begin{array}{c}-0.670^{* * *} \\
(0.157)\end{array}$ & $\begin{array}{c}-0.636^{* * *} \\
(0.152)\end{array}$ & $\begin{array}{c}-0.687^{* * * *} \\
(0.158)\end{array}$ \\
\hline IB $\times$ Treat & $\begin{array}{c}0.141 \\
(0.181)\end{array}$ & $\begin{array}{l}0.0285 \\
(0.165)\end{array}$ & $\begin{array}{c}0.162 \\
(0.182)\end{array}$ \\
\hline Post $\times$ Treat & $\begin{array}{l}0.881^{* * *} \\
(0.155)\end{array}$ & $\begin{array}{c}0.836^{* * *} \\
(0.156)\end{array}$ & $\begin{array}{c}0.881^{* * *} \\
(0.155)\end{array}$ \\
\hline Post $\times$ IB & $\begin{array}{l}-0.203^{* *} \\
(0.0941)\end{array}$ & $\begin{array}{l}-0.208^{* *} \\
(0.0944)\end{array}$ & $\begin{array}{l}-0.206^{* *} \\
(0.0941)\end{array}$ \\
\hline Post $\times$ Treat $\times$ IB & $\begin{array}{c}-0.436^{* *} \\
(0.204)\end{array}$ & $\begin{array}{c}-0.508^{* *} \\
(0.205)\end{array}$ & $\begin{array}{l}-0.397^{* *} \\
(0.201)\end{array}$ \\
\hline Post $\times$ Treat $\times$ IB $\times$ Green & $\begin{array}{c}-1.055^{* * *} \\
(0.224)\end{array}$ & & $\begin{array}{c}-1.115^{* * *} \\
(0.221)\end{array}$ \\
\hline Post $\times$ Treat $\times$ IB $\times$ Sannong & & $\begin{array}{c}-1.788^{* * *} \\
(0.133)\end{array}$ & $\begin{array}{c}-2.028 * * * \\
(0.137)\end{array}$ \\
\hline Quarter FE & Yes & Yes & Yes \\
\hline Bond Info. & Yes & Yes & Yes \\
\hline Bond Issuer Info. & Yes & Yes & Yes \\
\hline Market Info. & Yes & Yes & Yes \\
\hline Macro Factors & Yes & Yes & Yes \\
\hline Obs. & 1,757 & 1,757 & 1,757 \\
\hline Adjusted $R^{2}$ & 0.638 & 0.635 & 0.640 \\
\hline
\end{tabular}

Note: Regression equation is specified by (8), with the additional interaction terms of Post $_{t} \times$ Treat $_{i} \times I B_{i}$ with Green and Sannong. We report only the results with all controls. Robust standard errors are clustered at the bond level. ${ }^{* * *},{ }^{* *}$, and ${ }^{*}$ represent statistical significance at $1 \%, 5 \%$ and $10 \%$, respectively. 
Table 13: Shopping for Venue in Primary Markets: Logit Regression Results

\begin{tabular}{lcccc}
\hline \hline Variables & $(1)$ & $(2)$ & $(3)$ & $(4)$ \\
\hline \multirow{2}{*}{ Treat } & & & & \\
& $\begin{array}{c}2.047^{* * *} \\
(0.256)\end{array}$ & $\begin{array}{c}2.307^{* * *} \\
(0.249)\end{array}$ & $\begin{array}{c}2.367^{* * *} \\
(0.251)\end{array}$ & $\begin{array}{c}2.491^{* * *} \\
(0.268)\end{array}$ \\
L.Post $\times$ Treat & $0.384^{* *}$ & $0.389^{*}$ & $0.441^{* *}$ & $0.473^{* *}$ \\
& $(0.192)$ & $(0.199)$ & $(0.205)$ & $(0.233)$ \\
& & & & \\
Month FE & Yes & Yes & Yes & Yes \\
Bond Info. & Yes & Yes & Yes & Yes \\
Bond Issuer Info. & No & Yes & Yes & Yes \\
Market Info. & No & No & Yes & Yes \\
Macro Factors & No & No & No & Yes \\
\hline Obs. & 3,075 & 3,042 & 3,042 & 3,026 \\
\hline \hline
\end{tabular}

Note: Results are repored from a logistic regression as specified by 10. L.Post dummy takes value of 1 if the bond was issued after August 1, 2018: the application for the approval to issue such bonds would have been submitted after the policy shock date of June 1, 2018 because the NDRC typically takes 2-3 months to approve the bond issuance. Standard errors are clustered at the bond level. ${ }^{* * *},{ }^{* *}$, and ${ }^{*}$ represent statistical significance at $1 \%, 5 \%$ and $10 \%$, respectively. 
Figure 1: Balance of PBOC's Collateral-based Lending Facilities

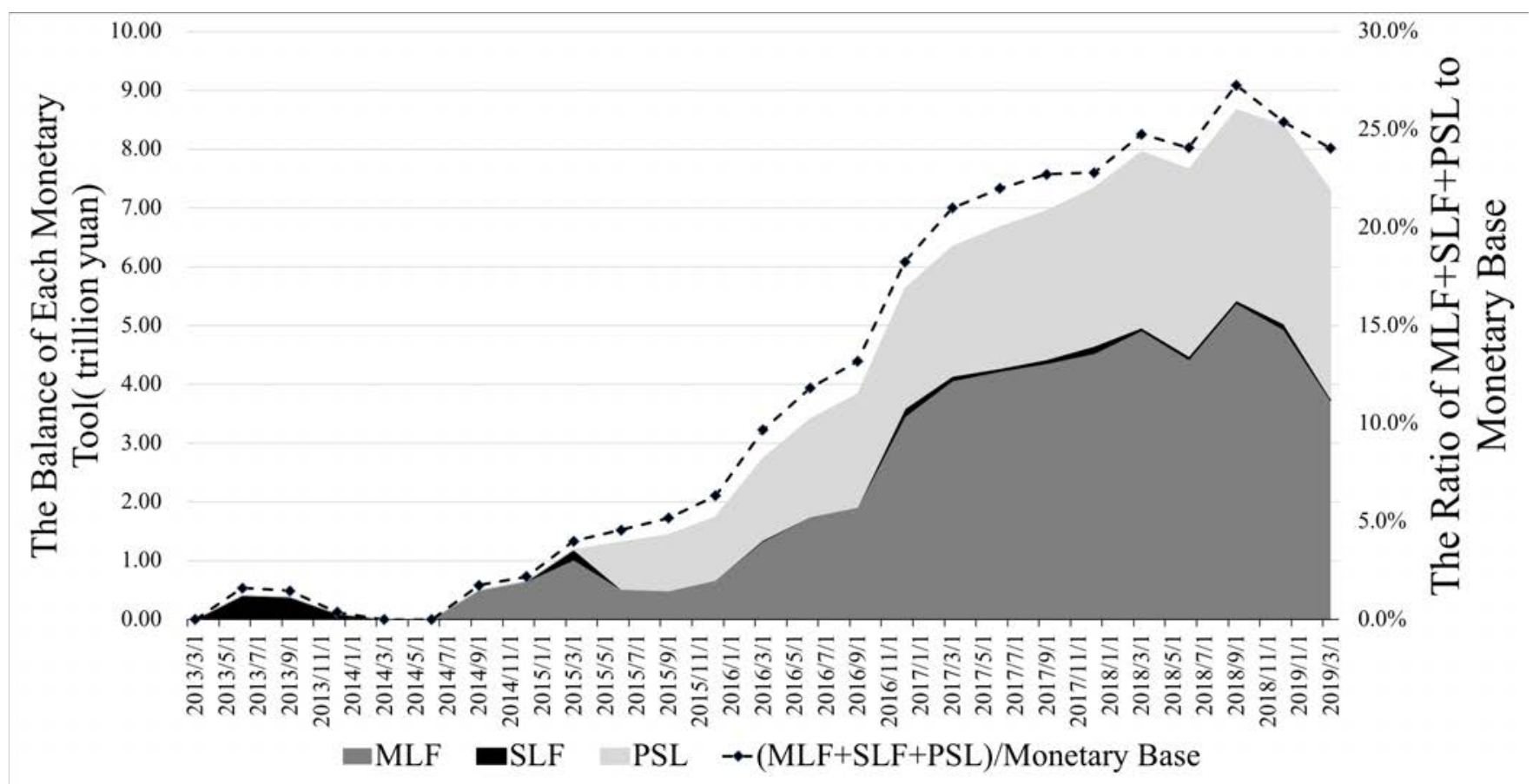

Note: Statistic is calculated by authors according to data reported by People's Bank of China, obtained from WIND, as of May 30th 2019. 
Figure 2: Liquidity Transmission Mechanism of Traditional and Unconventional Monetary Policies in China
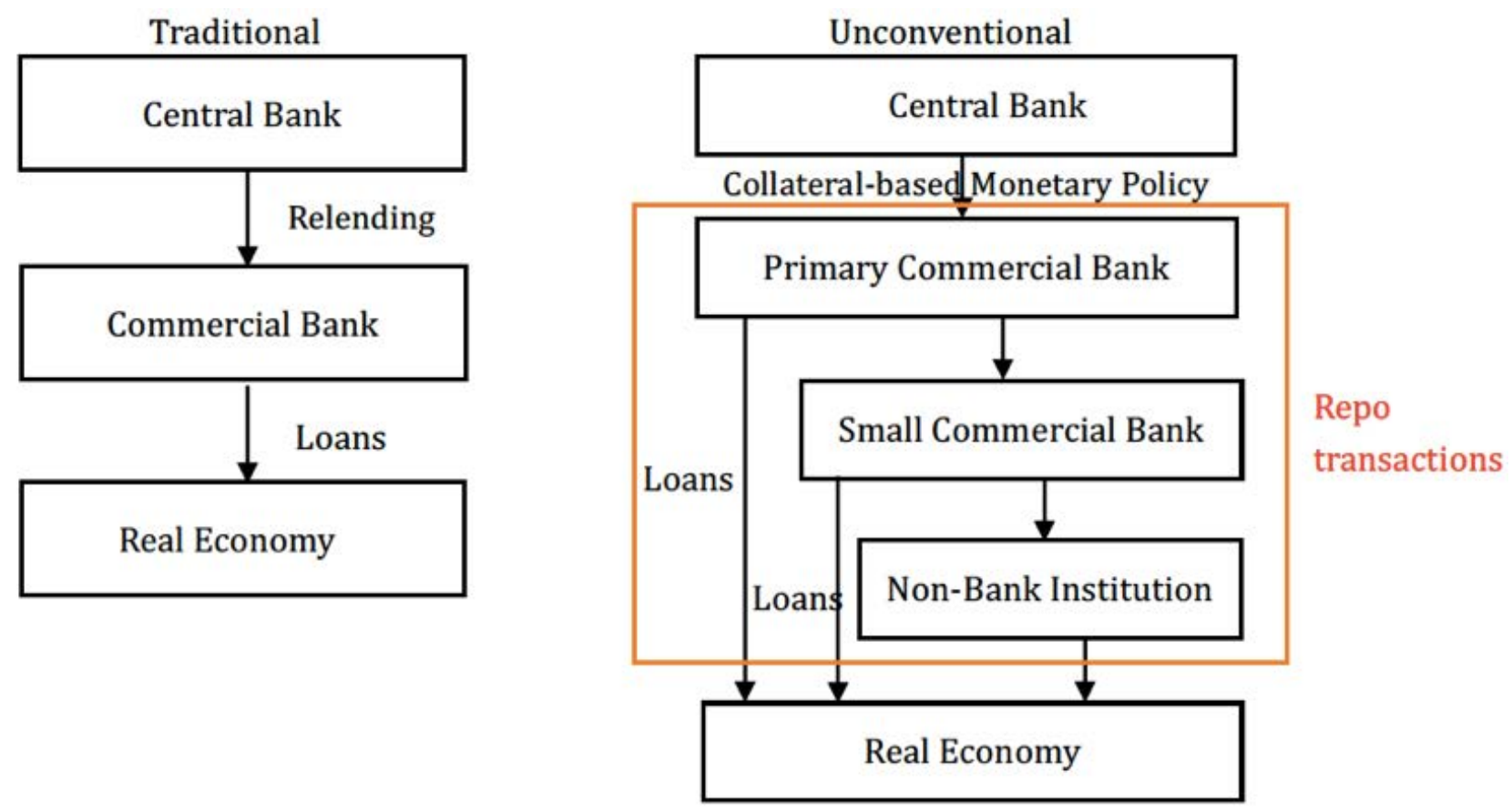
Figure 3: Average Daily Spread of Bonds in the Exchange Market and the Interbank Market Before and After the Expansion of MLF Collaterals on June 1, 2018: Secondary Market
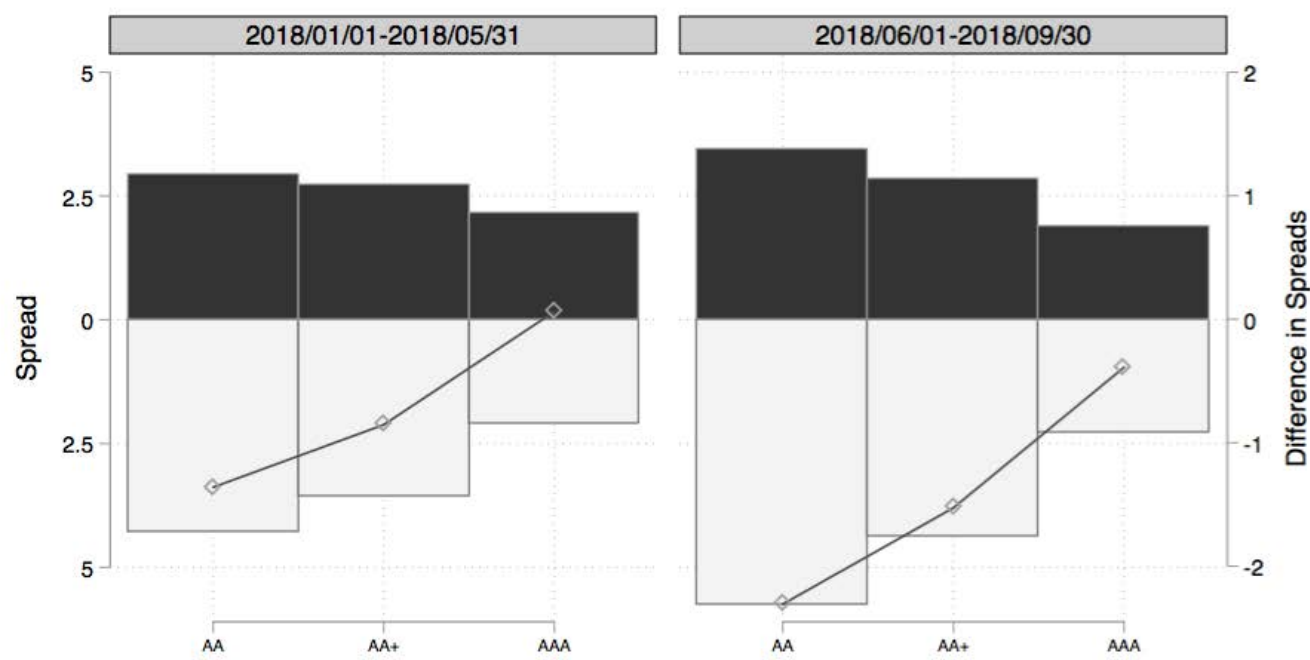

Rating of Bonds

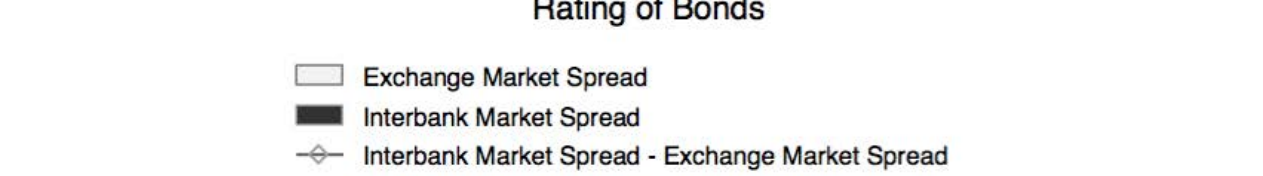

(a) Full Sample
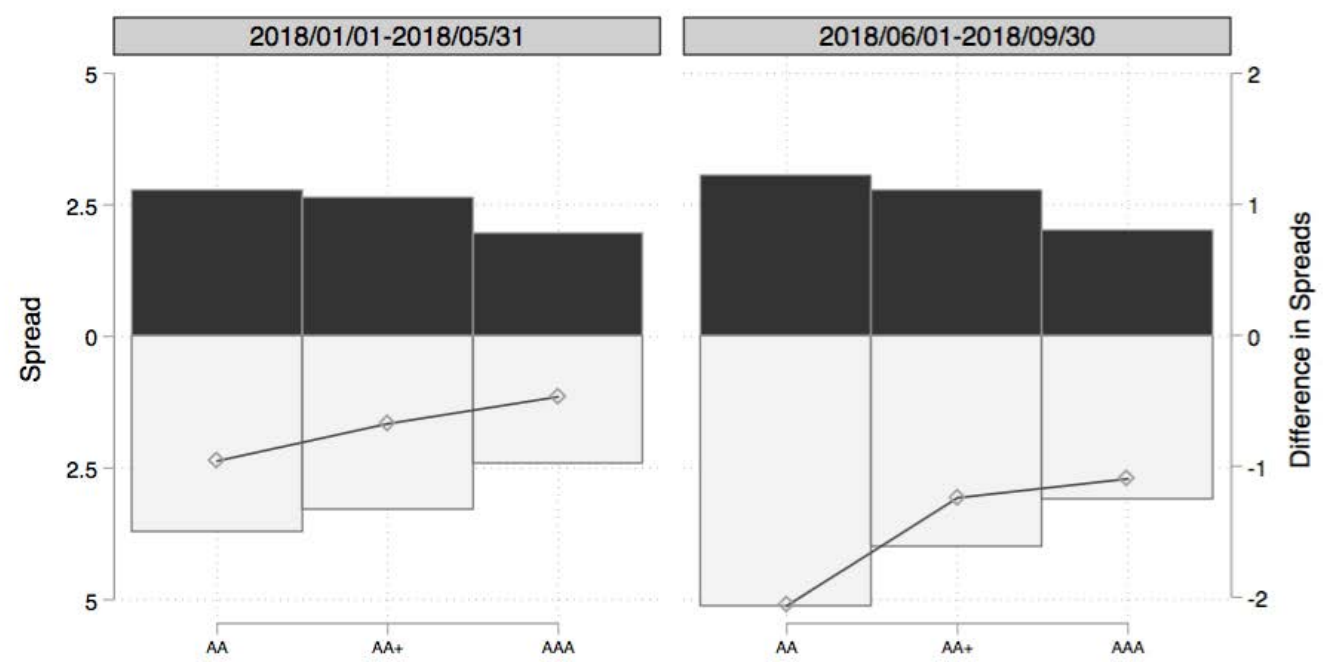

Rating of Bonds

Exchange Market Spread

Interbank Market Spread

$\dashv-$ Interbank Market Spread - Exchange Market Spread

(b) Dual-listed Bonds Only

Note: The sample period of left graph is 01/01/2018-05/31/2018. Panel (a) uses the full sample; and Panel (b) uses dual listed bonds only. The sample period of right graph is 06/01/2018-09/30/2018. The horizontal axis denotes the three rating of bonds. The darker bar is the average spread in interbank market, the lighter bar is the average spread in exchange market (left scale). The solid line depicts the difference between the two spreads (right scale). 
Figure 4: Spread Differences Between the Interbank and the Exchange Market, by Bond Ratings: Secondary Market

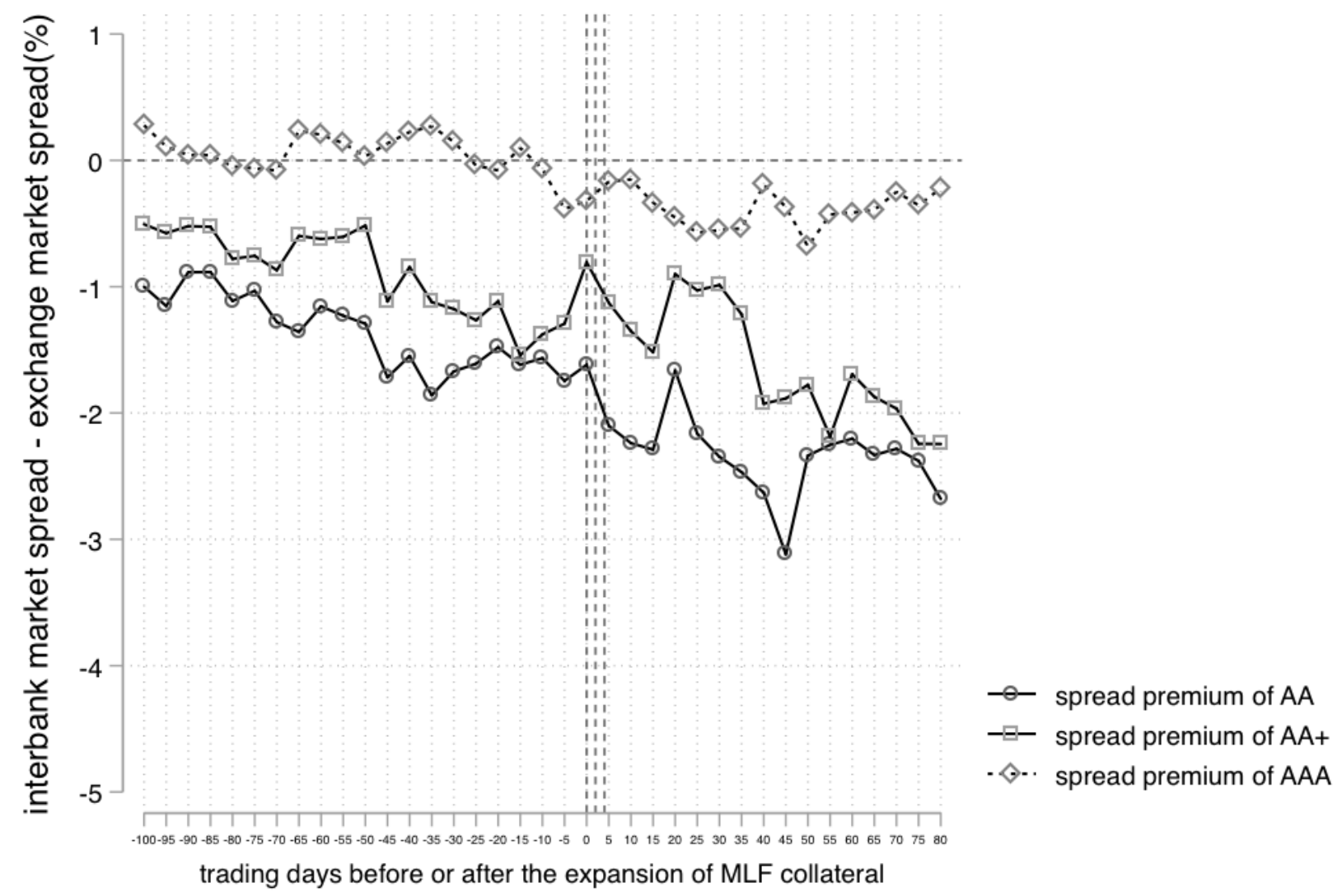

Note: Date 0 is June 1, 2018, the date of the policy shock. The graph covers the period of 01/01/2018-09/30/2018. Each point represents the average spread premium in 5 day window, where average spread premium $=$ average spread of bonds in the interbank market - average spread of bonds in the exchange market. The black, blue and green line depicts the change of spread premium of AA, AA+ and AAA bonds over time. 
Figure 5: Kernal Distribution of Absolute Difference Between Spreads of Dual-listed Bonds in Interbank Market and Exchange Market: Secondary Market

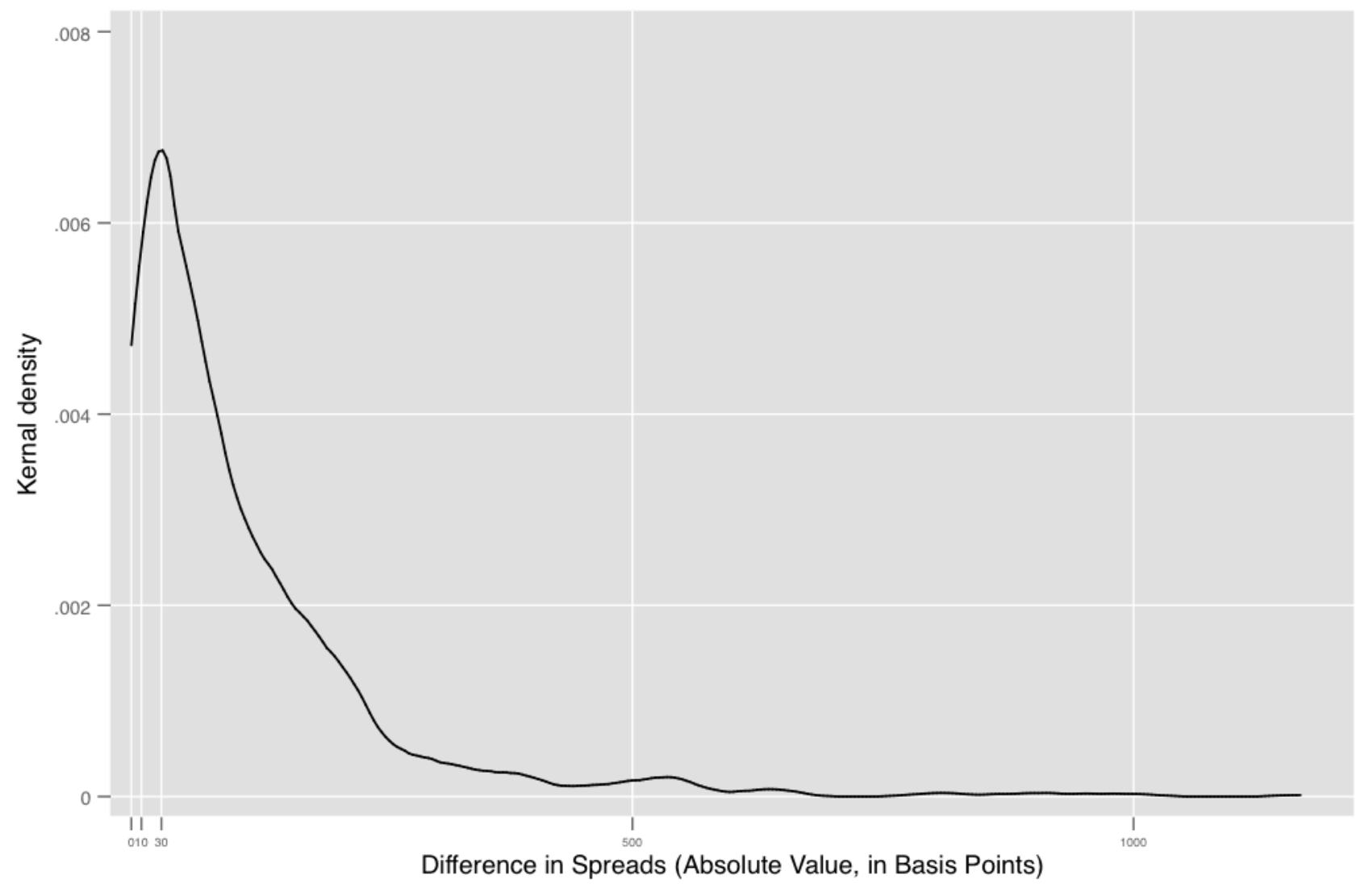


Figure 6: Parallel Pre-Trend and Time Patterns of Policy Effects in the Secondary Market

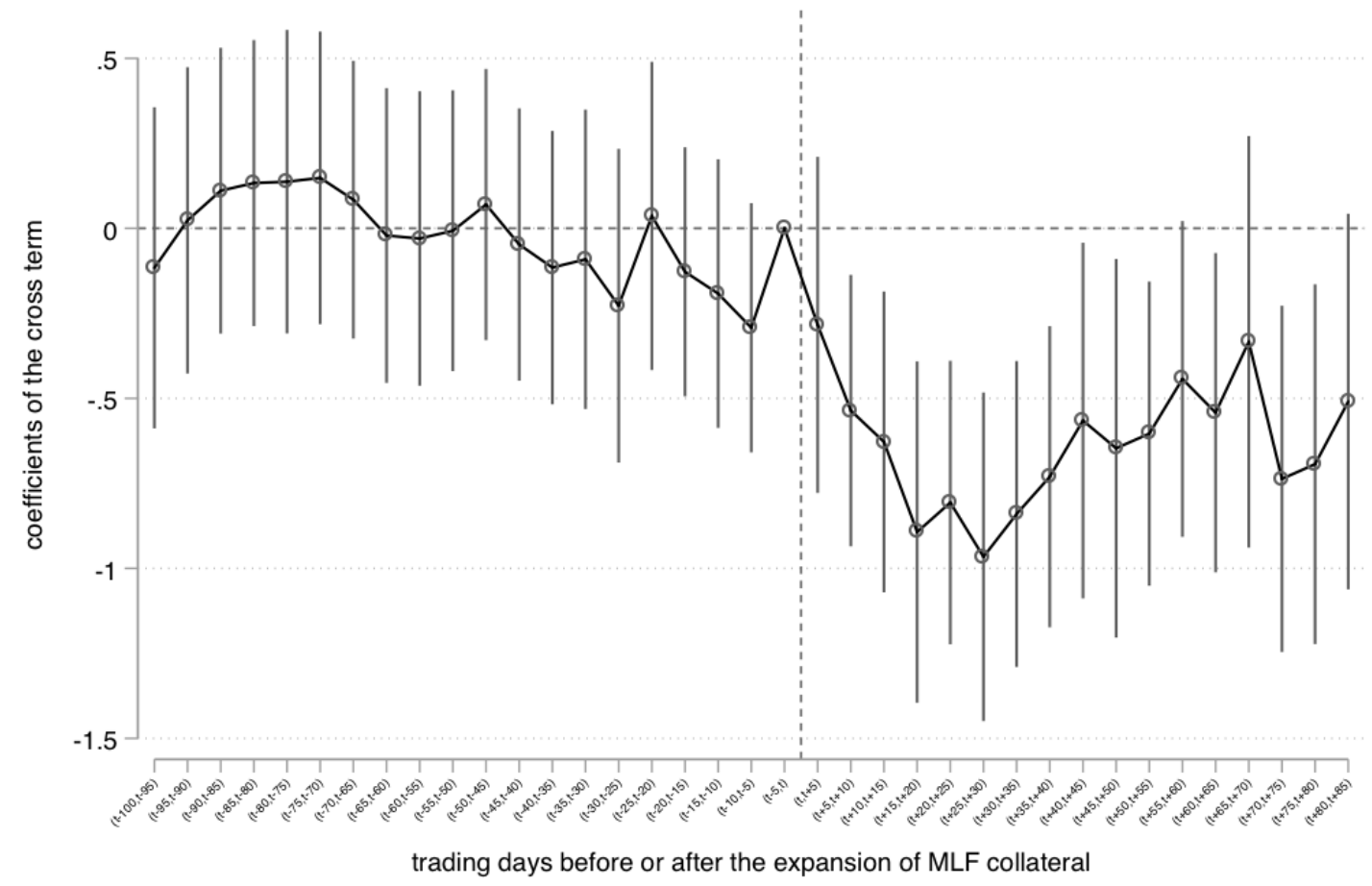

(a) Full Sample

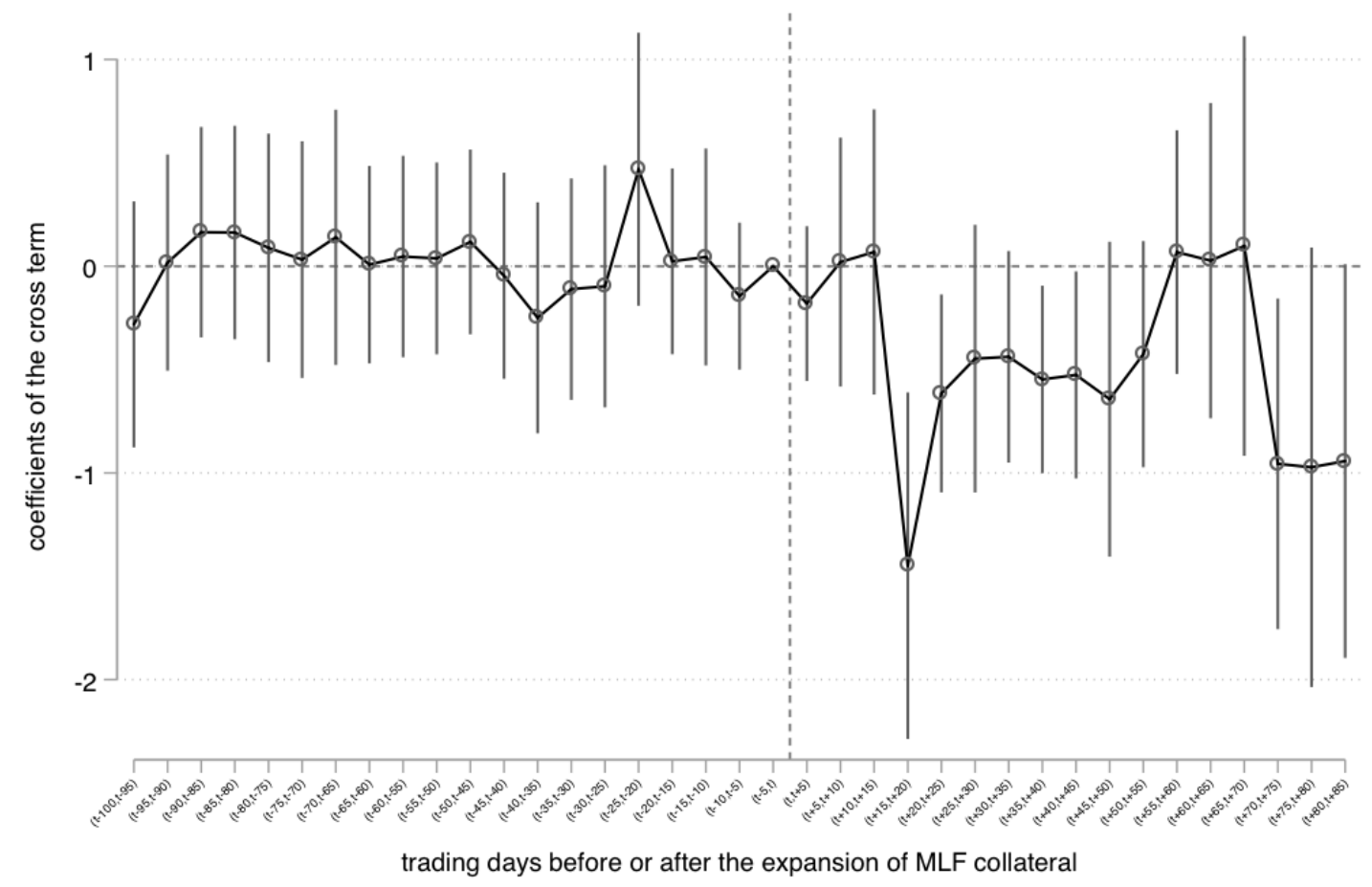

(b) Dual-listed Bonds Only

Note: Each dot in window $[t-5+5 k, t+5 k]$ stands for the point estimate of coefficient $\alpha_{k}$ in regression equation (3). The vertical whisk around the point is the associated $95 \%$ confidence interval. The point in window $[t-5, t]$ is normalized to 0 . 
Figure 7: Spread Differences for Primary Market between the Interbank and the Exchange Markets, by Bond Rating: Primary Market
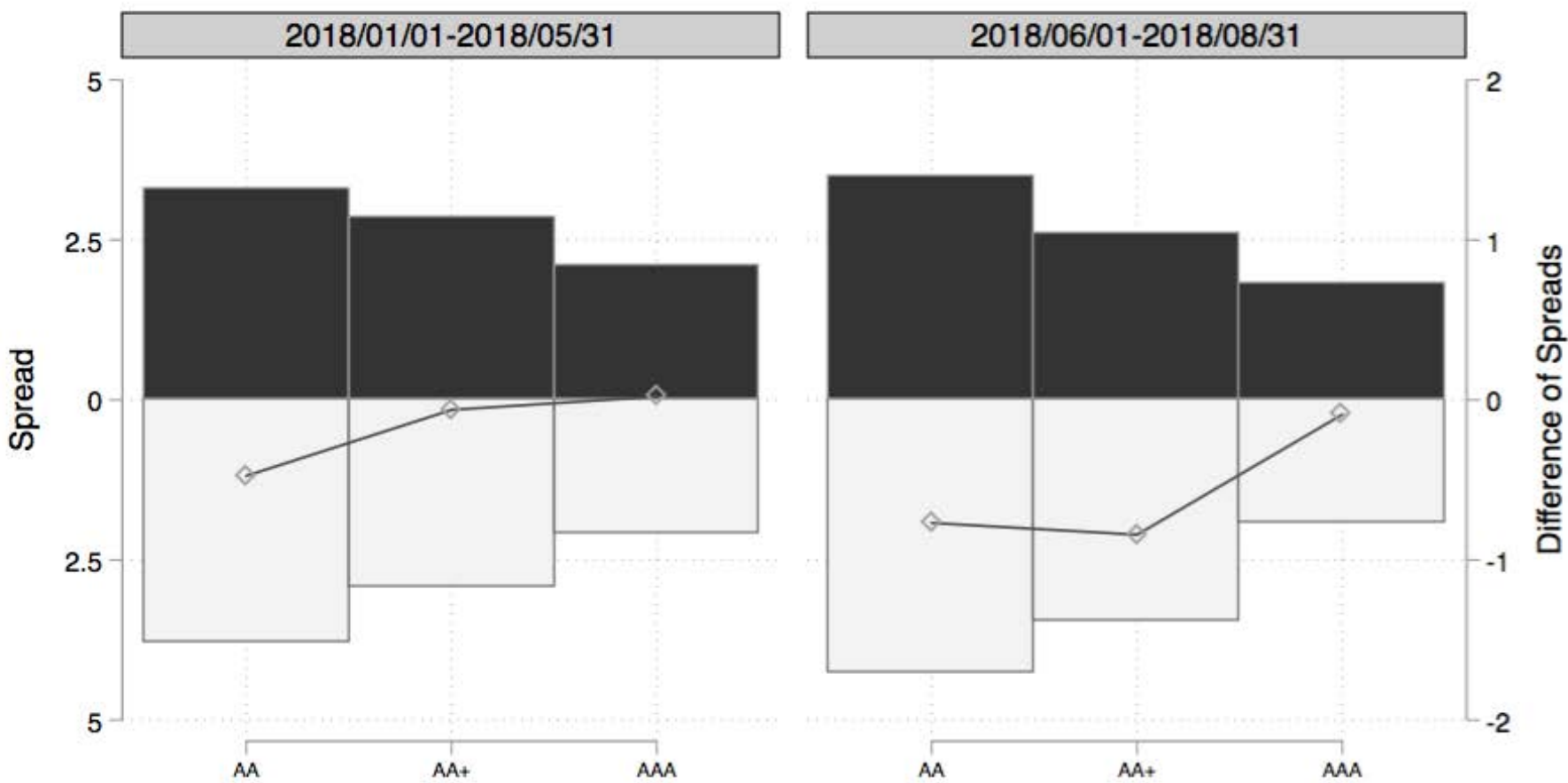

Rating of Bonds

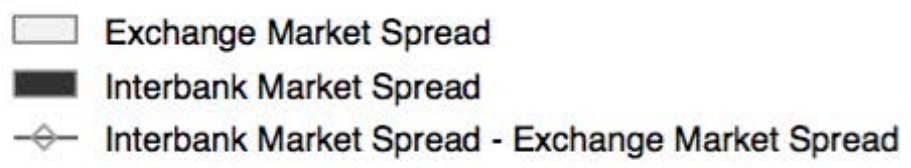

Note: The sample period of left graph is $01 / 01 / 2018-05 / 31 / 2018$. The sample period of right graph is 06/01/2018-8/31/2018. The horizontal axis denotes the three rating of bonds. The lighter bar is the average spread in exchange market, the darker bar is the average spread in interbank market (left scale). The solid line depicts the difference between the two spreads (right scale). 
Figure 8: Primary Market Data: Spreads Before and After June 1, 2018

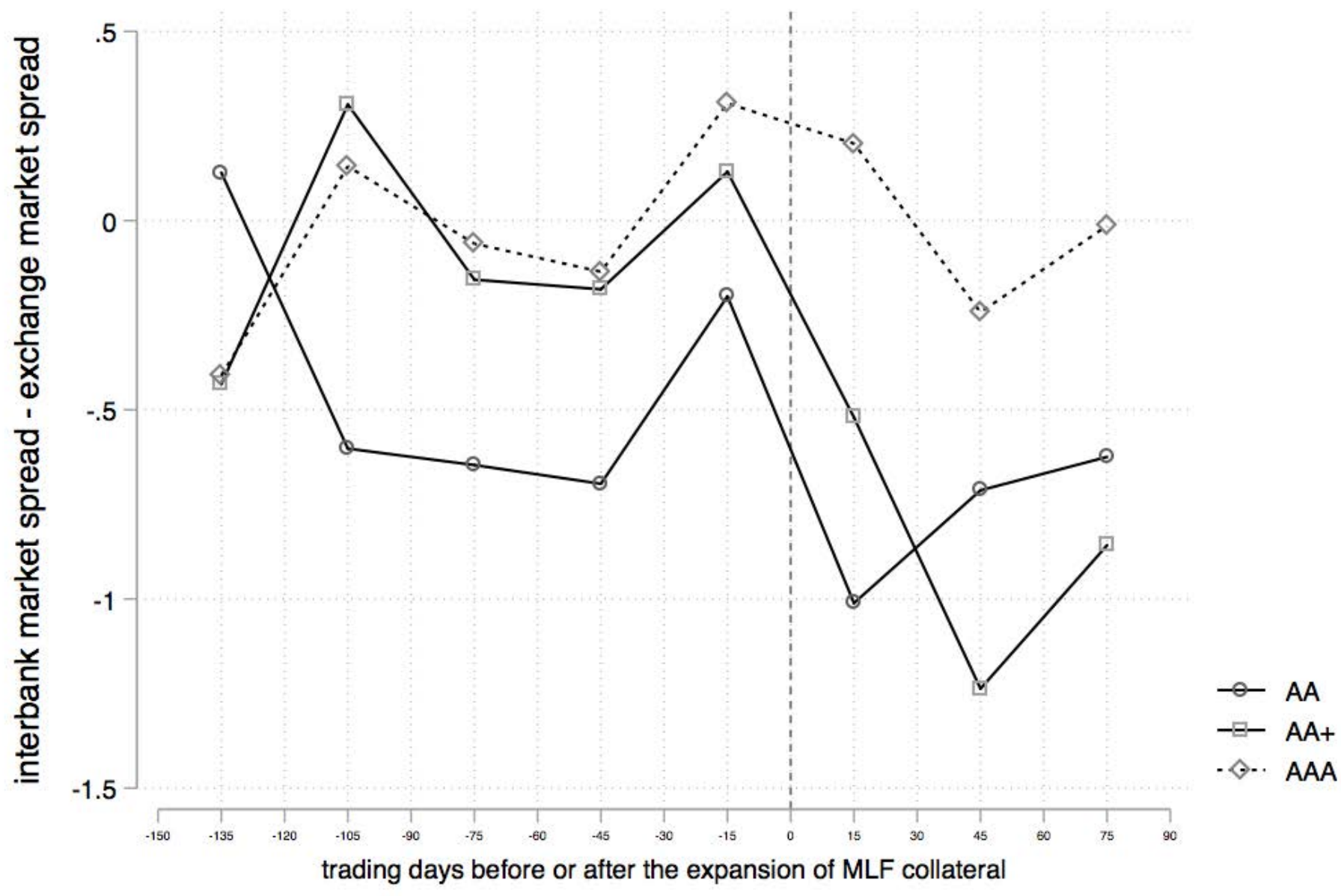

Note: The sample period of the graph is 01/01/2018-08/31/2018. Each point represents the average difference of spread at issuance between the interbank market and the exchange market in 5-day windows, where average spread difference is simply the average spread at issuance interbank market bonds minus the average spread at issuance of exchange market bonds. 
Figure 9: Parallel Trend and Dynamic Effects: Primary Market

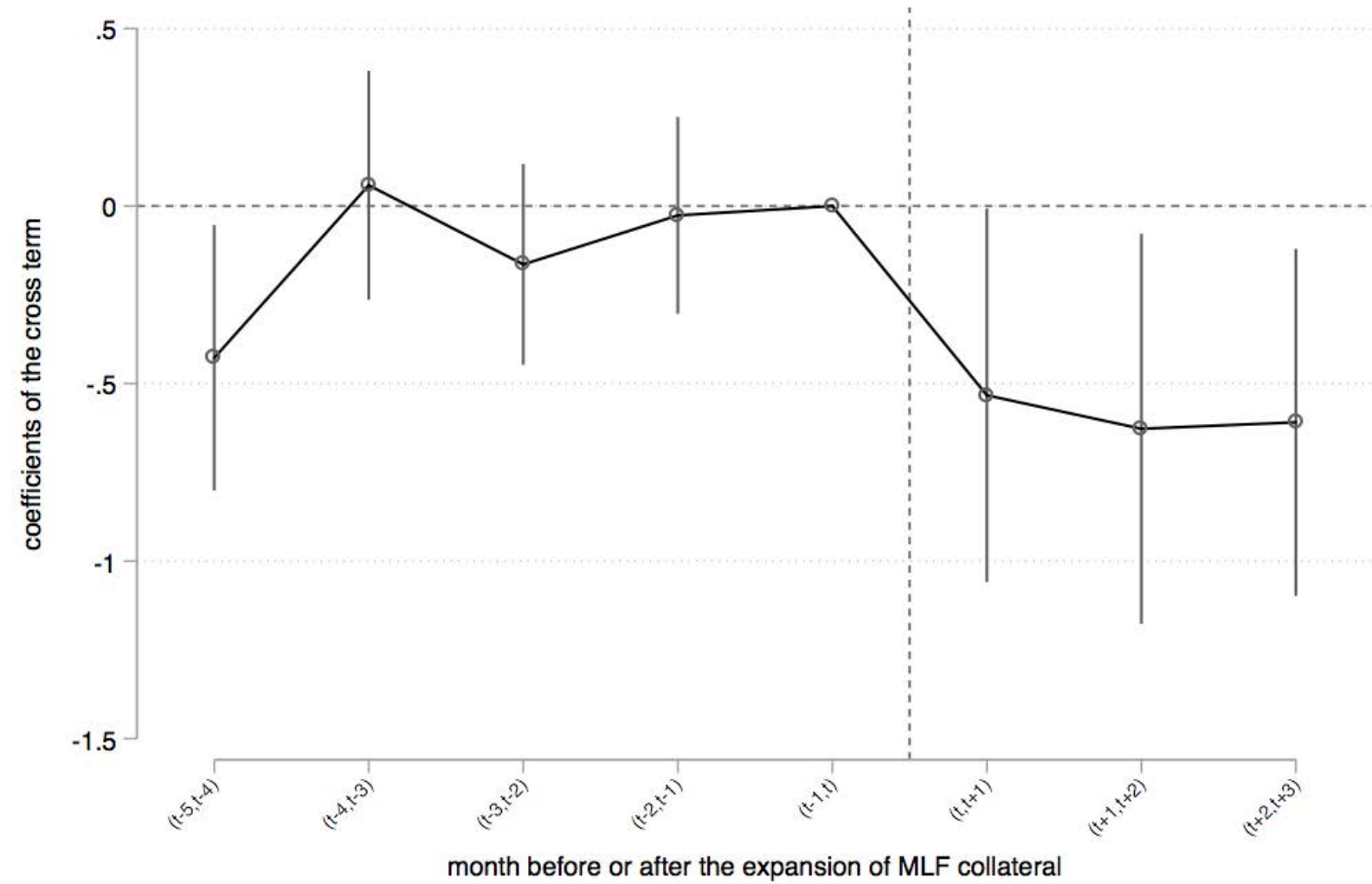

Note: Each dot in window $[t-1+k, t+k]$ stands for the point estimate of coefficient $\alpha_{k}$ from equation (9). The vertical whisk around the point is the associated $95 \%$ confidence interval. The point in window $[t-1, t]$ is normalized to 0 . 
Table A.1: Summary Statistics for the Primary Market Data: 2018/1/1-2018/12/31

\begin{tabular}{|c|c|c|c|c|c|c|c|c|c|c|c|c|c|c|c|c|}
\hline $\begin{array}{l}\text { Panel A } \\
\text { Variables }\end{array}$ & & \multicolumn{5}{|c|}{$\begin{array}{l}\text { Full Sample } \\
\end{array}$} & \multicolumn{5}{|c|}{\begin{tabular}{l}
\multicolumn{2}{c}{ Interbank Market } \\
Mean Std.Dev. Min Min
\end{tabular}} & \multicolumn{5}{|c|}{ Exchange Market } \\
\hline Dep.Var. & & 3076 & Mean & Sta.Dev. & 0.232 & 5.889 & ODS & Miean & Std.Dev. & Min & $\operatorname{Max}$ & UDS & Miean & Sta.Dev & $1 \mathrm{Min}$ & 5889 \\
\hline \multirow{3}{*}{ Dummies } & & 5,010 & 2.010 & 1.108 & & & & & & & & 1,101 & 2.530 & 1.220 & & \\
\hline & L.Post & 3,076 & 0.519 & 0.500 & o & 1 & 1,889 & 0.522 & 0.500 & 0 & 1 & 1,187 & 0.513 & 0.500 & 0 & 1 \\
\hline & $\begin{array}{l}\text { IB } \\
\text { Treat }\end{array}$ & 3,076 & 0.614 & 0.487 & $\begin{array}{l}0 \\
0\end{array}$ & 1 & 1,889 & $\stackrel{1}{0}$ & 0 & 1 & 1 & 1,187 & 0 & 0 & 0 & 0 \\
\hline \multirow{6}{*}{ Bond Info } & & & & & 000900 & & & & & & & & & & & \\
\hline & Quantity (Billion RMB) & 3,076 & 1.494 & 2.657 & 0.00900 & 43 & 1,889 & 1.634 & 3.281 & 0.0800 & 43 & 1,187 & 1.271 & 1.045 & 0.00900 & 7.200 \\
\hline & Guarantee & $\begin{array}{l}3,076 \\
3,076\end{array}$ & 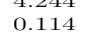 & $\begin{array}{l}1.861 \\
0.318\end{array}$ & 0.918 & 10 & $\begin{array}{l}1,889 \\
1,889\end{array}$ & $\begin{array}{l}4.386 \\
0.105\end{array}$ & $\begin{array}{l}2.049 \\
0.306\end{array}$ & $\begin{array}{l}2 \\
0\end{array}$ & $\begin{array}{c}15 \\
1\end{array}$ & 1,187 & $\begin{array}{l}4.017 \\
0.129\end{array}$ & $\begin{array}{l}1.489 \\
0.335\end{array}$ & $\begin{array}{l}0.917 \\
0\end{array}$ & 15 \\
\hline & SOE & 3,076 & 0.791 & 0.406 & o & 1 & 1,889 & 0.863 & 0.343 & 0 & 1 & 1,187 & 0.676 & 0.468 & 0 & 1 \\
\hline & Put & 3,076 & 0.323 & 0.468 & 0 & 1 & 1,889 & 0.149 & 0.356 & 0 & 1 & 1,187 & 0.600 & 0.490 & 0 & 1 \\
\hline & Call & 3,076 & 0.114 & 0.318 & o & 1 & 1,889 & 0.163 & 0.370 & 0 & 1 & 1,187 & 0.0371 & 0.189 & 0 & 1 \\
\hline \multirow[t]{5}{*}{ Issuer Info } & Detb Asset Ratio & 3,076 & 63.30 & 18.11 & 0 & 95.59 & 1,889 & 63.19 & 18.66 & 0 & 95.38 & 1,187 & 63.47 & 17.20 & 0 & 95.59 \\
\hline & Liquidity Ratio & 3,076 & 3.606 & 54.82 & o & 2887 & 1,889 & 4.392 & 68.59 & o & 2887 & 1,187 & 2.356 & 17.30 & 0 & 420.6 \\
\hline & Cash Coverage Ratio & 3,076 & 0.531 & 2.049 & -2.571 & 3.024 & 1,889 & 0.449 & 2.070 & -2.571 & 3.024 & 1,187 & 0.661 & 2.010 & -2.571 & 3.024 \\
\hline & Log Assets & 3,045 & 25.03 & 1.457 & $\begin{array}{l}16.09 \\
1609\end{array}$ & 30.73 & 1,873 & 25.04 & 1.499 & 16.09 & 30.73 & 1,172 & 25.00 & 1.388 & 19.93 & 29.86 \\
\hline & Log Equity & 3,043 & 23.87 & 1.276 & 16.09 & 29.00 & 1,871 & 23.88 & 1.299 & 16.09 & 29.00 & 1,172 & 23.87 & 1.240 & 19.35 & 27.71 \\
\hline \multirow[t]{3}{*}{ Market Info } & Similar Bond Issuance (Billion RMB) & 3,076 & 5.287 & 5.757 & 0.0300 & 70.50 & 1,889 & 5.507 & 6.463 & 0.0800 & 70.50 & 1,187 & 4.938 & 4.386 & 0.0300 & 18.32 \\
\hline & CMB Issuance (Billion RMB) & 3,076 & 22.04 & 37.51 & 0 & 259.0 & 1,889 & 15.24 & 23.27 & 0 & 129.5 & 1,187 & 32.85 & 50.94 & 0 & 259.0 \\
\hline & 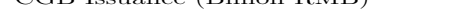 & 3,076 & 16.00 & 58.04 & 0 & 500.2 & 1,889 & 15.74 & 48.52 & 0 & 250.1 & 1,187 & 19.00 & 70.58 & 0 & 500.2 \\
\hline \multirow{9}{*}{ Macro Info } & $\triangle$ GDP & 3,050 & 10.49 & 3.377 & -13.58 & 20.30 & 1,873 & 10.42 & 3.340 & -13.58 & 20.30 & 1,177 & 10.60 & 3.432 & -13.58 & 20.30 \\
\hline & $\Delta \mathrm{M} 2$ & 3,076 & 8.781 & 0.243 & 8.174 & 9.233 & 1,889 & 8.786 & 0.249 & 8.174 & 9.233 & 1,187 & 8.772 & 0.234 & 8.174 & 9.233 \\
\hline & $\mathrm{IB} \times \mathrm{AA}+$ & 3,076 & 0.164 & 0.370 & 0 & 1 & 1,889 & 0.267 & 0.443 & 0 & 1 & 1,187 & 0 & 0 & 0 & 0 \\
\hline & $\mathrm{IB} \times \mathrm{AAA}$ & 3,076 & 0.281 & 0.449 & o & 1 & 1,889 & 0.457 & 0.498 & 0 & 1 & 1,187 & 0 & 0 & 0 & o \\
\hline & RRRcut $\times$ IB & 3,076 & 0.447 & 0.497 & 0 & 1 & 1,889 & 0.727 & 0.445 & 0 & 1 & 1,187 & 0 & 0 & 0 & 0 \\
\hline & RRRcut $\times$ AA + & 3,076 & 0.166 & 0.372 & 0 & 1 & 1,889 & 0.178 & 0.383 & 0 & 1 & 1,187 & 0.147 & 0.354 & 0 & 1 \\
\hline & RRRcut $\times$ AAA & 3,076 & 0.396 & 0.489 & 0 & 1 & 1,889 & 0.345 & 0.476 & 0 & 1 & 1,187 & 0.476 & 0.500 & 0 & 1 \\
\hline & RRRcut $\times$ IB $\times$ AA+ & 3,076 & 0.110 & 0.312 & 0 & 1 & 1,889 & 0.178 & 0.383 & 0 & 1 & 1,187 & 0 & 0 & 0 & 0 \\
\hline & RKFCUt $\times$ IB $\times$ AAA & 3,060 & & 0.409 & & & 1,889 & 0.345 & 0.466 & & & 1,187 & 0 & 0 & & 0 \\
\hline \multirow{2}{*}{\multicolumn{2}{|c|}{$\begin{array}{l}\text { Panel B } \\
\text { Bond Rating } \\
\end{array}$}} & \multirow{2}{*}{\multicolumn{5}{|c|}{ Full Sample }} & \multicolumn{5}{|c|}{ Interbank Market } & \multirow{2}{*}{\multicolumn{5}{|c|}{ Exchange Market }} \\
\hline & & & & & & & $\mathrm{Ol}$ & & & Per & ent & & & & & \\
\hline \multirow{4}{*}{ Rating } & & \multirow{4}{*}{\multicolumn{2}{|c|}{$\begin{array}{c}540 \\
820 \\
1,716 \\
3,076\end{array}$}} & \multicolumn{3}{|c|}{17.56} & $3:$ & & & & & & 84 & & 15.5 & \\
\hline & $\mathrm{AA}+$ & & & & 26. & & $5:$ & 51 & & & & & 69 & & 22.6 & \\
\hline & AAA & & & & 55. & & 98 & 32 & & & & & 34 & & 61.8 & \\
\hline & Total & & & & 10 & & 1,8 & 89 & & & & & 187 & & 10 & \\
\hline Panel C & & & & Full Sam & & & & Ints & erbank $\mathrm{N}$ & Iarket & & & Exc & hange $M$ & arket & \\
\hline Bond Type & & $\mathrm{Ol}$ & & & Perc & & $\mathrm{Ol}$ & os. & & Per & ent & $\mathrm{Ol}$ & bs. & & Perc & \\
\hline & Corporate Bonds & 27 & & & 89. & & 16 & 96 & & & & & 662 & & $89.4>3$ & \\
\hline & - Enterprise Bonds & & & & 9.3 & & 28 & & & & & & 2 & & $0.17-5$ & \\
\hline Туре & - Exchange-traded Corporate Bonds & 1,0 & 60 & & 34. & & & & & & & & 600 & & 89. & \\
\hline & - Medium-term Notes & 1,4 & 12 & & 45. & & 1,4 & 12 & & & & & - & & $-{ }_{-1}$ & \\
\hline & Financial Bonds & & & & 10. & & $1 !$ & & & & & & 25 & & 10.5 & \\
\hline & Total & 3,0 & 76 & & 10 & & 1,8 & 389 & & & & & 187 & & 10 & \\
\hline Panel D & (Billion RMB) & & & Full Sam & le & Tot & 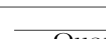 & Inte & erbank $\mathrm{N}$ & Iarket & 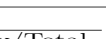 & 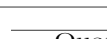 & Exa & hange $M$ & arket & Total 20 \\
\hline & (Billion RMB) & Qua & ntity & & Quantit. & Total & Qua & ntity & & Quantit & y/Total & Qua & intity & & Quantity & Total \\
\hline & Corporate bonds & 3,16 & 0.9 & & 68. & & $1,9:$ & 37.7 & & & & 1,22 & 23.20 & & 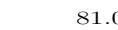 & \\
\hline & - Enterprise Bonds & 24 & 5.9 & & 5.3 & & 24 & & & & & & 200 & & 0.12 & \\
\hline Issuance & - Exchange-traded Corporate Bonds & 1,2 & 21 & & 26. & & & & & & & & 221 & & 80. & \\
\hline & - Medium-term Notes & 1,6 & 94 & & 36. & & 1,6 & 994 & & & & & & & - & \\
\hline & Financial Bonds & 1,4 & 134 & & 31. & & 1,1 & 49 & & & & 28 & 5.2 & & 18.9 & \\
\hline & Total & $4,5 !$ & 34.9 & & 10 & & 3,08 & 36.7 & & & & $1,5 \mathrm{c}$ & 08.4 & & 100. & \\
\hline
\end{tabular}

Note: See text in Section 5 for details of the variables. This summary statistics table include all new bond issued between 2018/1/1 and 2018/12/31, which are used in the analysis for Table 13 where we test for the hypothesis of venue shopping. 